\title{
Improving Child Health and Cognition: Evidence from a School-Based Nutrition Intervention in India
}

\author{
Marion Krämer ${ }^{1}$, Santosh Kumar ${ }^{2}$, Sebastian Vollmer ${ }^{3}$
}

\begin{abstract}
We present experimental evidence on the impact of delivering double-fortified salt (DFS), salt fortified with iron and iodine, through the Indian school-feeding program called "mid-day meal" on anemia, cognition, and math and reading scores of primary school children. We conducted a field experiment that randomly provided one school-year supply of DFS at a subsidized price to public primary schools to prepare mid-day meal in one of the poorest regions of India. The DFS treatment had significantly positive impacts on hemoglobin levels and reduced the prevalence of anemia by 20 percent but these health gains did not translate into statistically significant impacts on cognition and test scores. While exploring the heterogeneity in effects, we find that treatment had statistically significant gains in anemia and test scores among children with higher treatment compliance. We further estimate that the intervention was very cost effective and can potentially be scaled up without much financial burden.
\end{abstract}

JEL Codes: C93, I15, I18, O12.

Keywords: Double-fortified salt, education, anemia, cognition, school-children, midday meal, India, and randomized controlled trial.

\footnotetext{
${ }^{1}$ Krämer: Department of Economics, University of Goettingen, Germany (marion.kraemer@wiwi.unigoettingen.de); ${ }^{2}$ Kumar: Department of Economics and International Business, Sam Houston State University, Huntsville TX, USA (skumar@shsu.edu); ${ }^{3}$ Vollmer: Department of Economics \& Centre for Modern Indian Studies, University of Goettingen, Germany (svollmer@ uni-goettingen.de).

We thank Achyuta Adhvaryu, Abhiroop Mukhopadhyay, Aimee Chin, Darren Grant, Elaine Liu, Hiranya Nath, Kartini Shastry, Mehtabul Azam, Nishith Prakash and conference participants at the Hidden Hunger Meeting (Hohnheim, Germany), Global Food Symposium (Gottingen, Germany), ACEGD 2017 (ISI, Delhi), ADRI (Patna, India), and SEA 2017 for valuable feedbacks. We immensely thank Abhijeet Kumar and MORSEL for primary data collection and field inputs and the Foundation Fiat Panis as well as the German Research Foundation (DFG)-RTG 1666 for providing financial support. This study is registered in the AEA RCT Registry and the unique identifying number is: "AEARCTR-0002957". An earlier version of this study was shared as "Impact of delivering ironfortified salt through a school feeding program on child health, cognition and education: Evidence from a randomized controlled trial in rural India". This version supersedes all the previous versions.
} 


\section{Introduction}

Access to better nutrition in children is crucial for human capital formation and human welfare, especially in developing countries, where $40 \%$ of the children are stunted and suffer from chronic undernutrition. In India, $50 \%$ of daily under-five deaths are caused by micronutrient deficiencies. ${ }^{1}$ While several methods of improving childhood micronutrient malnutrition have been attempted, the empirical evidence on the effectiveness of different strategies to deliver micronutrients is mixed and unsettled. Salt fortification could be an effective channel for iron delivery; however, previous research that focused on salt fortification to reduce iron-deficiency and market delivery channel failed to reduce malnutrition. A recent experiment of providing subsidized or free double fortified salt (DFS), salt fortified with iron and iodine, through village shops failed to reduce malnutrition in India (Banerjee, Barnhardt, and Duflo 2018).

Instead of the market institution, this paper tests the effectiveness of a non-market institution, school infrastructure, in delivering micronutrients to school children, and examines the short-run causal impacts of DFS on child health, learning outcomes, and educational attainment in rural India. Our study uses the government-mandated midday meal program in primary schools as a vehicle for micronutrient supplementation and estimates the causal impacts of DFS intervention on micronutrient status, cognitive functions, and educational outcomes of school children in rural India.

Except for Berry et al. (2017), no experimental studies have utilized school infrastructure, specifically school lunch programs, to deliver nutrients to school-age children in India. ${ }^{2}$ In resource-poor settings faced with the low take-up of micronutrient supplementation and slow diffusion of fortified products, health clinics or schools could be a potential channel to increase take-up as well as compliance with supplementation programs (Chong et al. 2016). Higher compliance has been found to be effective in improving health in Indonesia (Thomas et al. 2006) but maintaining high and consistent compliance remains a challenge in micronutrient supplementation programs when households have to make a choice. In this context, school lunch

\footnotetext{
${ }^{1}$ Micronutrient deficiencies are mainly lack of iron, iodine, zinc, vitamins etc.

${ }^{2}$ In an experimental study, Berry et al. (2017) evaluate the impact of school mid-day meal fortified with micronutrient mix as well as Iron and Folic Acid supplementation in India and find no significant impact either on child health or on learning outcomes.
} 
programs could be a viable strategy to increase the compliance rate for micronutrient supplementation program.

Adequate nutrition, including both micro- and macro-nutrients, is critical for human capital formation, which broadly includes education, cognitive skills, and health of individuals. Previous studies have emphasized the importance of early childhood nutritional interventions on formation of human capital (Bloom, Canning and Jamison 2004, Currie and Vogl 2013, Baird, et al. 2016), particularly because their effects are thought to accumulate over time and have long-lasting impacts on adult outcomes (Lozoff, et al. 2006, Maluccio, et al. 2009). Given the strong link between early life conditions and adult outcomes, targeting school-age children is important because they are often less prioritized in terms of micronutrient interventions than preschoolers or pregnant women. In this context, school-based intervention could be an important channel for targeted intervention in this age group to improve children's health and their human capital formation.

Iron deficiency anemia (IDA) is a particularly widespread nutritional deficiency, with 20 percent of the world's population at risk of being anemic. Anemia prevalence among school-aged children is estimated to be as high as 50 percent (World Health Organization 2008). The global prevalence of anemia in children aged 6-59 months is $43 \%$, and the prevalence rate of $59 \%$ in India is substantially above the global average (International Institute for Population Sciences 2015). IDA is considered a leading risk factor for childhood mortality and morbidity, and is linked to impaired brain development and cognitive functions (Halterman, et al. 2001, Bobonis, Miguel and Puri-Sharma 2006). Increased iron consumption has been shown to positively impact health and cognitive development (Beard 2008; Kretchmer, et al. 1996). In our study sample, close to $50 \%$ of the children in the 5-10 year old age group are anemic.

While solving the problem of micronutrient malnutrition through fortification, policymakers have to grapple with the difficult choices of identifying appropriate food items to fortify and the delivery channel that can ensure high compliance rate. Different strategies and technologies have been proposed to increase iron intake, for example, nutritional supplements, food fortification, including salt fortification, and dietary diversification. Various means to deliver these products have also been tested through retail markets, agricultural extensions, and public institutions such as hospitals or schools. 
Fortification is likely to be preferred over supplementation programs because it is believed to have a high compliance, as they substitute for the conventional product and do not require significant behavioral change. Among different types of fortification programs (food, grain, and oil), salt fortification is considered a promising channel to deliver iron due to the steady and ubiquitous consumption of salt, irrespective of location and socioeconomic status or food preferences. However, the empirical evidence on the effectiveness of fortified products as well as the delivery channels is mixed and unclear. When rural households were offered DFS in Bihar, India at a subsidized price through regular local shops or the Public Distribution System, take-up rate was consistently low (Banerjee et al. 2018). ${ }^{3}$

The literature on the impacts of the DFS intervention on child health and educational outcomes is also far from settled. In the study by Banerjee et al. (2018), which provided free or subsidized DFS through village shops to rural households in Bihar, the authors did not find "an economically meaningful or statistically significant impact on hemoglobin, anemia, physical health, cognition or mental health" after two years of treatment. In another school-based intervention, Berry et al. (2017) evaluated the impact of micronutrient mixed mid-day meal in rural India, but no impacts on hemoglobin as well as child health were found. Since there was no significant impact on child health, they further found null impacts on human capital measures of cognitive and learning outcomes. In contrast, Thomas et al. (2006) found large positive impacts of iron supplementation in an Indonesian study that had high compliance and large dosage. The insignificant impacts on child health could be due to low take-up rates, a smaller dosage of iron delivered through fortification, or shorter treatment duration (Banerjee et al. 2018; Berry et al. 2017). The mixed and limited evidence calls for better understanding of the proper delivery of effective technologies to combat anemia because adoption of new technologies often depends on household's learning, preference, and local context.

In this paper, we examine another potential channel to increase iron intake: India' school feeding program, the "mid-day meal (MDM)". The mid-day meal is provided free of cost to all school children who attend a public school up to grade eight. As in Banerjee et al. (2018), the setting of our study is Bihar, one of the poorest states in

\footnotetext{
${ }^{3}$ Public Distribution System distributes subsidized food and non-food items to people identified as poor by means-testing.
} 
India. We selected two blocks of Jehanabad district where the MDM is cooked at schools. We supplied DFS for preparation of the MDM at a subsidized price for one school year to 54 primary schools that were randomly allocated to the treatment group, and we had a control group of the same size. We analyzed the impact of the DFS intervention on hemoglobin and anemia, cognitive ability, and education outcomes of children who were in the second grade at the baseline. The baseline data was collected between November 2014 and January 2015, treatment started in August 2015, and the follow-up survey was implemented after a year in August 2016.

The main rationale for considering the MDM as the distribution channel of iron (and potentially other micronutrients) is that the usage of fortified products in a public school feeding program is not an individual decision but a governmental one, in contrast to the approach in Banerjee et al. (2018). Therefore, if properly implemented, it has the potential of high compliance, as using DFS in the MDM is comparable to a (partly) mandatory fortification policy (similar to Thomas et al. 2016). The usage of DFS in the MDM further enables a regular and nearly daily provision of iron dosage to children, which is the recommended proper intake. Since public schools' infrastructure is well established even in rural areas, nearly every village in India has a school, and many children from low-income households attend public schools, school-feeding programs can reach a larger fraction of high-risk population at low marginal cost. The MDM is likely a cost-effective distribution channel because an existing logistical infrastructure is already in place. A couple of other randomized trials have used school meals to deliver micronutrients to school-aged children: Van Stuijvenberg (2005) in South Africa, Zimmermann et al. (2003) in Morocco, Andang'o et al. (2007) in Kenya, Moretti et al. (2006), and Radhika et al. (2011) in India. All these studies found school feeding programs to be an effective distribution channel for micronutrients. Furthermore, since the treatment in our study is a substitution of conventional iodized salt by DFS, it is unlikely to crowd out other school activities (instructional time), a concern raised in other time- and resourceintensive supplementation programs. For example, Berry et al. (2017) found that effort by school officials on existing programs were crowded out by the introduction of the new health programs. Our intervention design is unlikely to crowd-out scarce resources from existing school activities. 
We find that, after one year of treatment, the prevalence of any form of anemia reduced by 20 percent and the prevalence of mild anemia reduced by approximately 30 percent. On average, we did not find statistically significant impacts of the intervention on cognitive ability or math and reading scores. However, we find positive treatment effects of about 0.2 standard deviations on math and reading scores in the subgroup of students who had more than 80 or 90 percent school-attendance. These students had greater exposure to treatment because they consumed the MDM more frequently at school. We believe the treatment period of one year could be too short to detect a significant impact on cognition and educational outcomes and improve the initial cognitive disadvantage. The other reason for null impacts on cognition could be that children are deficient in multiple micronutrients (vitamin A, zinc etc.) and providing iron-fortified food alone may not be effective in improving learning outcomes among children.

Our study differs from previous studies in substantive ways (sample age, amount of fortification, treatment duration, and delivery channel) and relates to the broader literature on the effectiveness of school-based micronutrient interventions on child health and cognition. To the best of our knowledge, this is one of the handful of studies that rigorously evaluates the usage of salt as an iron carrier in a school-feeding program to reduce the prevalence of nutritional deficiency in India. We depart from previous studies in two unique ways: (1) we rely on salt fortification instead of food fortification or supplementation and (2) we use mid-day meal program as a channel to distribute fortified salt, which is likely to ensure higher compliance. The other advantage of our intervention is the reduced possibility of crowding-out existing school activities that may impact child health and educational outcomes. Furthermore, in contrast to existing studies, we assess not only health but productive outcomes such as cognitive abilities and educational outcomes as well which are important for longrun human capital accumulation.

The remainder of this paper is structured as follows. Section 2 describes the intervention and the context. The study design and data are explained in section 3 , and section 4 outlines the estimation strategy. The estimation results are presented in section 5. In section 6, we discuss the challenges to the internal validity of our results, and in section 7, we perform a cost-effectiveness analysis of the intervention. We conclude in section 8 . 


\section{Context and intervention}

\subsection{India's school-feeding program}

By the mid-1980s, India's school-feeding program was started in the state of Tamil Nadu and Gujarat as an initiative of the respective state governments. The implementation of the MDM aimed to overcome classroom hunger, increase the nutritional level of school children, and enhance enrolment and attendance. It also aimed to reduce caste discrimination and improve gender equity. The mid-day meal program is one of the largest school-feeding programs, covering an estimated 104.5 million school children in 1.16 million schools in 2013-2014 (Ministry of Human Resource Development, 2016). The MDM in Bihar covers all children from grades one through eight (Ministry of Human Resource Development 2016).

Each child is supposed to receive a daily lunch meal that is predefined in calories and composition of food items. The menu is fixed by the state government for all schools and varies daily, but is repeated every week. In most Indian regions, including the state of Bihar, the MDM is prepared directly at schools in kitchens explicitly built for this purpose. ${ }^{4}$ The Food Corporation of India provides grains directly to the schools and a representative of the school, usually the headmaster, individually buys the remaining ingredients (for example vegetables, pulses, oils, and spices) at the local market. For every primary school child (grades one to five), schools receive 3.59 Rs. $(0.05 \mathrm{USD})^{5}$ per day from the government to cover the cost of the additional ingredients; for every upper-primary school child (grades six to eight) they receive 5.38 Rs. (0.07 USD) per day. The MDM is served every day except Sundays and holidays (Ministry of Human Resource Development 2016).

\subsection{Distribution of double fortified salt}

We delivered DFS to 54 randomly selected public schools in Bihar, India. The DFS was subsequently used to prepare the MDM at the school. The DFS formula has been developed by the National Institute of Nutrition (NIN) Hyderabad and is produced by a few private manufacturers. We purchased the DFS, Tata Salt Plus, from a large Indian private company (Tata Salt) and the salt was fortified with $0.86 \mathrm{mg}$ of iron per gram of iodized salt. The daily requirement of a child between 7 and 9 years of age is

\footnotetext{
${ }^{4}$ In other regions, mostly in urban areas, the MDM is prepared centralized in large kitchens or provided by organizations of international assistance.

${ }^{5}$ Average exchange rate 2016. 1 Rs. equals 0.015 USD.
} 
$10 \mathrm{mg}$, while for children between the ages of 4 and 6; it is $8 \mathrm{mg}$ (World Health Organization 1959). By matching the daily amount of salt used, as reported by the cooks, to the number of children that go to that school, we calculate that an average amount of $4 \mathrm{~g}$ of DFS per meal was served in our study. This implies that students received at least $3.5 \mathrm{mg}$ of iron per meal $(4 * 0.86)$, which accounts for approximately 35 percent of the daily iron requirement. At the average level of school attendance of $80 \%$, we estimate that students received $17.5 \mathrm{mg}$ of iron per week from our DFS intervention. Laboratory studies show good stability of the iron and iodine content of the NIN formula of DFS. In a few small-scale experimental studies, where regular consumption was closely monitored, acceptable increases in hemoglobin levels were found due to DFS consumption (Sivakumar, et al. 2001, Nair, et al. 2013).

In our study area, DFS was unavailable and mostly unknown throughout the study region. Starting in April 2012, DFS was sold in larger Indian cities; however, it did not stay on the market due to little demand. As instructed by the Department of Women and Child Welfare, DFS is supposed to be available in governmental food security programs, including the Integrated Child Development Program and the midday meal Scheme (Mudur 2013). However, this instruction is not enforced and consequently, the usage of DFS was still very limited due to supply-side bottlenecks and high cost. DFS cost $70 \%$ more than the conventional iodized salt sold in the local market. DFS was introduced in Bihar in early 2017 in its capital, Patna, which is a two to three-hour drive by car from the study region. But, throughout the study period, it was not available in the study region, which reduces concerns about contamination of the control groups.

We received DFS directly from the manufacturer and delivered it to the treatment schools either every month or two, depending on consumption. Headmasters were instructed to contact the study team if they ran out of DFS before the next delivery date. The regular school visits also functioned as a monitoring system (see section 6.1 for a detailed discussion of compliance with the treatment). To account for the potential budgetary effect, DFS was sold to headmasters at the subsidized price of Rs. 12 (0.18 USD), which is close to the price of non-DFS salt available locally. Since schools were already paying Rs 12 for the non-DFS salt, our intervention did not impose any additional financial burden on the treated schools. At the follow-up survey, headmasters and cooks stated that they did not have any major difficulties 
with the delivery and usage of the DFS. It should also be noted that students or their family members were not informed about the treatment and only the headmasters and cooks were aware of the intervention. ${ }^{6}$

\subsection{Conceptual framework}

Given that DFS is regularly used when cooking the MDM (an assumption that is discussed in section 6.1) and that children regularly attend school (an assumption that is discussed in section 5.2), we expect that the children's average hemoglobin value will increase and that anemia prevalence will go down. If positive effects on hemoglobin and anemia can be found, we would expect as a next step that cognitive skills and educational outcomes might be positively affected as well. Iron deficiency affects cognitive development through immediate neurobiological processes, i.e. the inhibition of the central nervous system to develop properly (e.g. the brain and the spinal cord) (Beard 2003), and causes "functional isolation." Children deficient in iron engage less with their environment, have fewer interpersonal interactions, show less attention, and are relatively unresponsive to stimuli in comparison to their noniron deficient counterparts. Thus, they have difficulties in accumulating new skills (Lozoff, et al. 1998). Cognitive development directly influences the educational outcomes of children. For example, if students are unable to focus their attention and ignore distractions, they are likely to have difficulties in acquiring new skills and knowledge. The same is likely to be true for the symptoms of anemia, such as frequent illness or tiredness (Halterman, et al. 2001, Bobonis, Miguel and PuriSharma 2006).

\section{Study design and data}

\subsection{Sample and randomization}

The study was conducted in the two blocks of Kako and Modanganj in the Jehanabad district, located in the state of Bihar, India. A simple random sample of 108 schools was drawn prior to the DFS intervention from a list of 228 public schools within the two selected blocks. From these 108 schools, 54 were randomly allocated

\footnotetext{
${ }^{6}$ The usage of DFS in the MDM had already been instructed by an official note of the Central Government (Mudur 2013). By sending their children to public schools, parents allow them to participate in the MDM and hence agree to the consumption of DFS as well.
} 
to the treatment group. The remaining 53 schools did not receive any treatment and formed the control group and the control group continued to use the conventional iodized salt, and one school was inaccessible at endline due to monsoon flooding, therefore, had to be excluded from the study. A computer-generated list of random numbers was used for the allocation of the treatment and control groups.

On average, 20 children from the second grade were randomly selected from each of the 108 schools for the survey, which resulted in an initial sample size of approximately 2000 children. Second graders were chosen because of the strong biological basis for post-infancy effects of iron deficiency on the neurobiological development of the brain. Specifically, the frontal lobes continue to develop until adolescence and experience spurts of development between the ages of 7 and 9, as well as in the mid-teens (Anderson 2002, Hudspeth and Pribram 1990, Thatcher 1991). Children in the second grade are about 6-7 years old, hence they are coming up on one of their critical, post-infancy periods of brain development. Among other functions, the frontal lobes are known to mediate advanced interrelated cognitive skills. These include the so-called executive functions, such as response inhibition, task switching, planning and organizing, working memory, abstraction, initiation, self-monitoring and volition (Anderson 2001, Lezak 1995, Salimpoor and Desrocher 2006).

\subsection{Data}

Between November 2014 and January 2015 a baseline survey was carried out. Implementation of the treatment was delayed because of the earthquake in Nepal in 2015 that also affected Bihar and led to a postponement of school holidays. It was further delayed because of a contract teacher strike, which led to many schools ceasing operations for several months. Therefore, treatment began in August 2015. An endline survey with the same children was administered from August to October 2016, approximately 12 months after treatment started. Three different teams collected data at both the baseline and endline. The endline survey was similar to the baseline survey and in general was focused on household demographics, socioeconomic characteristics, children's health \& cognitive ability, educational outcomes, diet quality, access to health care, and school characteristics. 
The first team went to the homes of the children to get parental consent for participation in the study and to conduct a parental interview. A second team visited the schools and performed cognitive and educational tests on the children. They also interviewed the headmasters and cooks and observed the cooking and distribution of the MDM. The third team was comprised of local medical staff that performed medical tests, including a blood test for hemoglobin levels. These tests were done at the children's homes or in their villages to give the parents the opportunity to attend the procedure.

\section{Outcome variables}

Anemia - The hemoglobin level of each child was assessed directly in the field by a minor blood test administered through the portable HemoCue ${ }^{\circledR} \mathrm{Hb} 301$ device $(\mathrm{AB}$ Leo Diagnostics, Helsinborg, Sweden). In both the baseline and endline surveys, less than one percent of the children refused the hemoglobin test. The demand for the medical check was very high, as parents perceived the health survey as a free health check-up. According to the World Health Organization (WHO, 2011), we define any anemia as a hemoglobin value $<11.5 \mathrm{~g} / \mathrm{dl}$, mild anemia as a hemoglobin value $\geq 11 \&$ $<11.5 \mathrm{~g} / \mathrm{dl}$, moderate anemia as a hemoglobin value $\geq 8 \&<11 \mathrm{~g} / \mathrm{dl}$ and severe anemia as a hemoglobin value $<8 \mathrm{~g} / \mathrm{dl}$. We only observed a few cases of severe anemia at baseline and endline and thus collapsed moderate and severe anemia into one category.

Cognitive ability - Cognitive ability was measured by five different cognitive tests: forward digit-span, backward digit-span, block design, Stroop-like day-and-night test, and Raven's Colored Progressive Matrices (Hale, Hoeppner and Fiorello 2002, Carlson 2005, Anderson 2001, Gerstadt, Hong and Diamond 1994, Raven and Court 1998). These are frequently used measures of cognitive ability for child populations. For example, the forward and backward digit-span tests and the block design tests are tests from Malin's Intelligence Scale for Indian Children (Malin 1969), and the Indian adaptation of the Wechsler Intelligence Scale for Children (WISC). Most of the cognitive tests assess higher executive functions, described in 3.1, which are supposed to develop at the age of our sampled children. The sequence of cognitive and educational tests was administered in a one-to-one setting and on average lasted for about 15 minutes. Table A1 summarizes the test, and a more detailed description of the different indicators is provided in the appendix. 
Educational outcomes - In addition to five cognitive outcomes, we collected data on math and reading skills. The math and reading tests were adapted from the Annual Status of Education Report (ASER Centre 2014) test material developed by the Indian Non-Governmental Organization Pratham. Reading scores ranged from 0 to 4, while math scores ranged from 0 to 15 . Both scores were normalized using the procedure described below. ${ }^{7}$ We also captured school attendance from the school's official attendance record. The school attendance for each child was calculated by the total number of days that the child was present, divided by the total number of school days in the past 12 months before the survey. We use school attendance to estimate heterogeneous treatment effects by exposure to the treatment, e.g. by how frequently a student consumed the MDM. We further document that school attendance is not affected by the treatment, which is reasonable because children were not aware of the DFS usage, and children who did not eat the MDM regularly could not improve their health and, indirectly their school attendance through the treatment.

\section{Covariates}

In accordance with the existing literature, we collected covariates that are often associated with the outcomes analyzed. For the anemia outcomes, these include socioeconomic characteristics (rural or urban, block dummy, wealth index ${ }^{8}$, father's years of schooling, mother's years of schooling, caste, religion and number of household members), nutritional factors (the children's dietary diversity score, or "diet quality", an indicator for household food security, the number of meals the child eats every day, the average intake of calories and iron from the school meal, an indicator for maternal health knowledge, if the child consumes any meat, poultry or fish, and if the child received iron supplements), access to health care (dummy for institutional delivery of the child and if any household member is covered by health insurance), morbidity indicators (if the child suffered from diarrhea in the last 30 days

\footnotetext{
${ }^{7}$ We normalized the cognitive test scores, math test score, and reading test score. We do this by subtracting the baseline mean of the control group and dividing by the baseline standard deviation of the control group of the given test, both for baseline and endline data. Hence, a normalized cognitive score of 0.5 would mean that the student scored 0.5 standard deviations higher than the mean in the baseline control group (irrespective of the sampling wave in which the score was obtained).

${ }^{8}$ The asset index was constructed by principle component analysis (PCA). The following variables were included in the PCA model: Type of toilet facility (improved and unimproved according to WHO), Source of drinking water, type of house, wall, roof and floor, possession of assets like chair, table, radio, pressure cooker etc., the amount of agricultural land owned, amount of different farm animals owned, BPL card holder, MNREGA card holder and the dependency ratio.
} 
and if the household had access to an improved sanitation facility), as well as gender of the child.

For the cognitive outcomes, the control variables included the same socio-economic indicators as above, along with the following set of nutritional factors (the children's dietary diversity score, an indicator for household food security, the number of meals the child eats every day, and the average intake of calories and iron from the school meal, an indicator for maternal health knowledge). Additionally, we collected indicators for psychosocial stimuli (dummy if the mother helps the child with its homework, the time the mother spends on giving physical care to the child, if parents participate in parent-teacher meetings at school and a dummy if the father lives in the household) and a dummy for identity of the test administrator. Further, indicators for quality of schooling (total school enrollment, student-teacher ratio, the number of children that attended second-grade at the baseline and the fourth-grade at the endline on the day of the interview and the distance to school in kilometers) were included in modeling the educational outcomes.

\section{Estimation strategy}

\subsection{Econometric specification}

We combine the randomized design with a difference-in-differences (DID) modeling approach. The DID approach exploits the cross-sectional and time variation in the treatment received by schools. Specifically, the DID estimator compares the difference in average outcome in the treatment and control groups before DFS intervention to the difference in average outcome in the treatment and control groups after DFS intervention. This approach enables us to control for any remaining observable and unobservable pre-intervention differences between groups that could confound our results. Our model further includes child fixed-effects and adjusts for additional time-variant covariates.

We estimate the DID model in the following ordinary least squares form:

$$
Y_{i s t}=\alpha_{i}+\beta_{1} \text { Post }_{t}+\beta_{2} \text { Post }_{t} * \text { Treat }_{s}+\delta_{1} S_{s t}+\delta_{2} X_{i t}+\epsilon_{i s t}
$$

where $Y_{i s t}$ is vector of outcomes for child $i$ at school $s$ at time $t . \alpha_{i}$ is the child-specific intercept. Post $t_{t}$ is a binary variable that takes the value of one for the post-treatment 


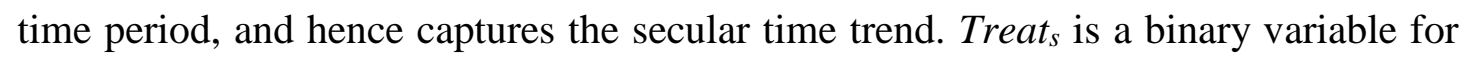
assignment to the treatment school. $S_{s t}$ is a vector of time-variant school control variables and $X_{i t}$ is a vector of time-variant child and household control variables, while $\epsilon_{i s t}$ is the error term. We include these control variables to account for any slight imbalances that the data may have and to increase the precision of our treatment effect estimates. Standard errors are clustered at the school level, the level of randomization. $\beta_{2}$ is the intention to treat (ITT) effect, the main coefficient of interest that estimates the causal effect of DFS on anemia, cognition, and learning outcomes. ${ }^{9}$ Since the treatment variable is constant within the child, the main effect of treatment $\left(\right.$ Treat $\left._{s}\right)$ is soaked up by the child fixed-effects, which is why it is omitted from equation (1).

We constructed a balanced panel for the anemia outcomes as well as for the cognitive and educational outcomes separately. Initially, we randomly sampled 2005 children - 20 children from each school. However, complete information on the health-related outcome variables (hemoglobin and anemia) and household characteristics was collected only for 1,791 observations at baseline. Of the baseline sample of 1,791 children, we collected hemoglobin values and the required covariates from the household questionnaire for 1,406 children at the follow-up survey (attrition is analyzed in section 4.3). Similarly, for the education sample at the baseline, we had 1,772 children with all of the required cognitive and educational outcomes, as well as household covariates. Of these 1,772 children, the cognitive and educational information and the household and school covariates were collected for 1,395 children in the follow-up survey. Therefore, the final analytical sample for anemia and educational outcomes, for which panel data are available, are 1,406 and 1,395 children, respectively.

\subsection{Sample characteristics and balance checks}

This section discusses the balancing of the two randomized groups with respect to baseline characteristics. As the allocation of schools into the treatment and the control groups was random, there should not be any systematic differences between the two groups at the time of the baseline survey. Table 1 presents the baseline characteristics for the anemia sample. The equivalent table for the cognitive and educational

\footnotetext{
${ }^{9}$ Since we do not directly observe participation in the treatment programs, our estimated effects are "intention-to-treat" treatment effects.
} 
outcomes is reported in the Appendix Table A4. Columns (5)-(8) show the baseline summary of the treated and the control groups as well as the $p$-values for the difference in means between the two groups for the baseline sample.

Table 1 reveals that the random assignment to the treatment group achieved a control group that is balanced on observed baseline characteristics, as there are no statistically significant differences between the two groups. All the control variables in Panel B and C are balanced across treatment and control at baseline. Furthermore, there is no evidence of an imbalance in the cognitive and educational sample (Appendix Table A4). In Table A4, pre-treatment characteristics of the sample in Panel $\mathrm{B}$ and $\mathrm{C}$ are almost identical across treatment and control groups at baseline (columns 5-8).

However, in panel A of Table 1, three out of 13 outcome variables (hemoglobin, any anemia, and mild anemia) are not perfectly balanced at the appropriate level of statistical significance. In the anemia sample, the baseline hemoglobin level was a bit higher in the control group, and the prevalence of anemia lower. The difference is small and negative in sign (children assigned to treatment schools have higher prevalence of anemia), indicating it would bias our estimates of causal impact of DFS on anemia/education downward, not upward. To further account for this difference, it is always controlled for in the DID model. Overall, these results strongly indicate that the randomization was successful and treatment status is likely to be orthogonal to observed and unobserved characteristics of the sample.

The summary statistics in Table 1 further reveal a picture of serious poverty characterized by high morbidity levels, low education, low socioeconomic status, low diet quality, and poor access to healthcare. The average incidence of anemia is $42 \%$, close to $45 \%$ anemia rate found in Banerjee et al. (2018). The average years of schooling for fathers and mothers is 5.5 and 1.7 years, respectively. The family size is large (about 7.9 persons) and the institutional delivery rate is $40 \%$. Furthermore, very few households have access to improved sanitation (7\%), but despite this low level of sanitation access, diarrheal prevalence is not very high (4\%). On average, a child receives 69 calories from pulses and vegetables and $3.5 \mathrm{mg}$ of iron per mid-day meal. The calorie estimation is based on the consumption of vegetables and lentils only; rice is not included because there was not much variation in per child consumption of rice 
across schools, because equal amount of rice per child was distributed to each school by government.

\subsection{Attrition}

Attrition is one issue that might threaten the internal validity of the treatment effects, particularly if the characteristics of the participants that are lost systematically differ between the treatment and control groups and if those characteristics are correlated with the outcome. If the attrition were related to treatment status, the treatment effects would be biased due to differences in unobserved characteristics across the experimental groups. In our survey, there is some attrition over time. The attrition rates are 21.4 percent (383/1789) and 21.8\% (377/1772) in the anemia and education sample, respectively. ${ }^{10}$ We address attrition concerns in two ways: (1) we checked whether attrition is correlated with the treatment status, (2) we conducted the baseline balance check on the endline or the attrited sample. ${ }^{11}$ There is no evidence of differential attrition, as attrition rates were similar across the treatment and the control groups. Of the $21.4 \%$ of children that were lost in the follow-up survey in the anemia sample, $48 \%$ were from the treatment group and 52\% from the control group. Of the $21.8 \%$ of the attrited children, $46 \%$ were in the treatment group and $54 \%$ in the control group, a difference of 8 percentage points. However, these differences in attrition rate by treatment status are not statistically significant (Table A3).

We further show that sample characteristics are overwhelmingly balanced across the treatment and control groups in the estimation sample (with attrition). In Table 1, we do not find any evidence of non-random attrition, as the pre-treatment characteristics of the two samples are nearly identical in the baseline, as well as estimation samples for the health outcomes (columns 1-4). In the Appendix Table A4, we perform the same exercise for the cognitive and educational sample and do not find any evidence of non-random attrition across treatment and control groups. The pre-treatment sample characteristics are balanced in the baseline as well as estimation samples in Table A4 (columns 1-4). The overall evidence shows that the post-attrition

\footnotetext{
${ }^{10}$ The baseline sample was 2,005 students. After refusals and non-availability, we could interview 1,791 students for the anemia outcome at baseline. Of these 1,406 students were reinterviewed at the follow-up survey.

11 This is within the normal range of other RCTs, for example Glewwe et al. (2009) report 25 percent attrition after one year of an intervention and a bit more than 30 percent two years after an intervention, and Ashraf et al. (2014) report 26 to 28 percent attrition in their follow-up survey.
} 
sample (estimation sample) has similar characteristics as the pre-attrition sample and is balanced between the treatment and the control groups.

\section{Results}

\subsection{ITT effects of DFS on Anemia and Test Scores}

The estimated impacts of the DFS intervention on multiple measures of anemia are presented in Table 2 and the impacts on cognition and education are presented in Table 3, respectively. The ITT estimates are based on specification (1). The first column shows estimates for hemoglobin levels and columns (2-4) show estimates for anemia related outcomes. All columns are estimated with child fixed-effects and the control variables discussed in the data section.

Anemia - Results in Table 2 show that the usage of DFS for the preparation of the MDM increased the average hemoglobin level by $0.136 \mathrm{~g} / \mathrm{dl}$. The estimated impacts are statistically significant and relatively small. Relative to the control group, we estimate a $1.2 \%$ increase in hemoglobin level associated with the DFS intervention. The size of the effect found in our study is comparable to the effects found in other DFS intervention studies among school-age children. The effect size of DFS intervention in other studies ranged from $0.5 \mathrm{~g} / \mathrm{dl}(4.5 \%)$ in India to $1.4 \mathrm{~g} / \mathrm{dl}$ in Morocco (Nair et al. 2013, Zimmermann et al. 2003). Another study by Sivakumar et al. (2001) found a significant decline in hemoglobin by $0.042 \mathrm{~g} / \mathrm{dl}$ among school children in the DFS treatment group at the end of 2 years of intervention in India. In a recent study, Banerjee et al. (2018) did not find significant impacts of free DFS on hemoglobin in a setting like ours. The mixed evidence on the DFS effectiveness in these studies could be due to the difference in the duration of the treatment, amount and type of fortification in the salt, physiological needs of the children, sample size, compliance, and age structure of the sample.

We next explore the impact of treatment on anemia prevalence. Results in column (2) in Table 2 indicate that treated students were 9.3 percentage points less likely to suffer from any form of anemia (hemoglobin $<11.5 \mathrm{~g} / \mathrm{dl}$ ). This translates to about 20 percent reduction in anemia prevalence in the treatment group relative to the control group. The usage of DFS in the MDM reduced the likelihood that a child suffers from mild anemia (hemoglobin $\geq 11 \&<11.5 \mathrm{~g} / \mathrm{dl}$ ) by 6 percentage points on average, 
which is equivalent to a reduction in the prevalence of mild anemia by nearly 30 percent (6.0/19.3). However, we do not find that the DFS reduced moderate or severe anemia. The sign is negative and in the right direction but the estimate is statistically insignificant. It seems that all of the effects on any anemia are coming from a reduction in mild anemia, as by construction, any anemia is the sum of mild and severe anemia.

The reduction in the prevalence of anemia is similar to the reduction found in other studies. Nair et al. (2013) reported a reduction in anemia by about $20 \%$ but Banerjee et al. (2018) were unable to find significant impacts on 10-14 year old children in Bihar, India. Analyzing data on 219 Peruvian adolescents, Chong et al. (2016) found a significant reduction in anemia by $34 \%$ among students who were anemic at baseline. Over 10 months of treatment, Andersson et al. (2008) found a significant reduction in anemia by $9-10 \%$ among 5-15 year old school children in rural southern India. The sample size in this study was 458 children. The overall results on hemoglobin and anemia incidence indicate that the intervention was effective in increasing hemoglobin levels and reducing anemia among second-grade school children in rural Bihar. Additionally, the treatment effects are robust to the inclusion of the socioeconomic characteristics of the households. The insignificant impacts of severe/moderate anemia may be due to the low dosage of iron in the fortified salt. When school children are consuming only one meal which has fortified salt (partial compliance), a low dosage of less than $1 \mathrm{mg}$ of iron per gram of salt may not have protective effects on children suffering from severe anemia.

The other reason for no impact on severe anemia could be due to hemoglobin ranges that are used to measure anemia types. Whereas mild anemia ranges from a hemoglobin value $\geq 11$ to $<11.5 \mathrm{~g} / \mathrm{dl}$, and thus has a span of 0.5 , moderate and severe anemia are defined as having hemoglobin values $<11 \mathrm{~g} / \mathrm{dl}$ and hence has a span of more than 3.0. The number of observations per discrete hemoglobin value is higher to the left of the mild anemia threshold than to the left of the moderate anemia threshold. Thus, even if the DFS treatment improves hemoglobin values marginally, the health gains to mildly anemic children are larger than moderately or severely anemic children. This could explain why a $1.2 \%$ increase in hemoglobin value due to DFS intervention results in 30 percent reduction in the incidence of mild anemia but no significant impacts on moderate or severe anemia. . 
Cognition and education - We next examine the impact of the DFS intervention on cognitive and educational outcomes. Results are presented in Table 3. As described in the data section, cognitive ability is measured by five different cognitive tests and educational outcomes are measured by scores on math and reading tests. All models account for household control variables and always include child fixed-effects. Panel A shows the results for cognition tests while Panel B shows the results for test scores and school attendance. Columns (1-5) in panel A of Table 3 measure the impact on different types of cognition tests and column (6) measures the impact on cognitive index, constructed using principal component method on outcomes in columns (1-5). We do not find a statistically significant treatment effects on any measures of cognitive or educational outcomes. None of the coefficients are statistically significant at conventional levels in Panel A. Even though the DFS treatment decreased the prevalence of any anemia by $20 \%$, on average, the one-year intervention of $3.5 \mathrm{mg}$ of iron per mid-day meal was not sufficient to improve the cognitive ability of second grade students. The cognitive index increased by 0.028 due to the treatment, but the results are statistically insignificant (column 6). In panel $\mathrm{B}$, we also do not find any significant impacts on math test scores or reading test scores. The estimates in the first two columns are positive but statistically insignificant. To summarize the findings in Table 3, the DFS treatment did not influence the cognition, test scores, or school attendance of the treated children, despite its significant impact on anemia.

\subsection{Heterogeneous effects by school attendance rate and household caste}

School attendance - We now investigate heterogeneity in the treatment effect by school attendance. It is likely that students who attended schools more regularly consumed MDM more frequently, and therefore, would have higher exposure to the treatment. Figure 1 shows the distribution of school attendance during the treatment period. To investigate the treatment effect at higher rates of school attendance, we centered the school attendance variable at 70, 80, and 90 percent, and then interact each centered attendance rate with the treatment dummy. The DID regression equation is as follows:

$$
\begin{aligned}
& Y_{i s t}=\alpha_{i}+\delta_{1} \text { Post }_{t}+\delta_{2} \text { School attendance }+\delta_{3} \text { Treat } * \text { Post }_{t}+\delta_{4} \text { Post }_{t} * \\
& \text { School atteandance }{ }_{i}+\delta_{5} \text { Treat }_{a} * \text { School attendance }_{i}+\delta_{6} \text { Post }_{t} * \text { Treat }_{a} * \\
& \text { School attendance } e_{i}+\gamma_{1} X_{s t}+\gamma_{2} W_{i t}+\epsilon_{i s t}
\end{aligned}
$$


where abbreviations are the same as those in equation (1). As shown in Table 3, the treatment did not have any effect on school attendance; therefore, the sub-analysis by school attendance is empirically valid. The DID estimates in Table 4 and 5 report estimates of the three coefficients $\delta_{6}$, i.e. the effect for a child with 70,80 , and 90 percent school attendance.

We consistently observe that the point estimates for all outcomes tend to increase with higher school attendance. The hemoglobin and anemia results at higher levels of school attendance are still statistically significant and the point estimates are larger than before (Table 4). Treatment effects for cognitive outcomes in Table 5 remain statistically insignificant. Treatment effects for math and reading scores become statistically significant at the 10 percent level for high levels of school attendance point estimates indicate an increase of almost 0.2 standard deviations. For the reading scores, the point estimate $(0.182)$ at $90 \%$ attendance is double the point estimate at $70 \%$ attendance.

Scheduled caste and Scheduled tribe - From a welfare perspective, it is also policyrelevant to investigate if children from socially disadvantaged communities (scheduled caste and scheduled tribe) have disproportionately large potential benefits from the intervention. ${ }^{12}$ We estimate the following specification:

$$
\begin{gathered}
Y_{\text {sit }}=\alpha_{i}+\delta_{1} \text { Post }_{t}+\delta_{2} S C / S T_{i}+\delta_{3} \text { Treat } * \text { Post }_{t}+\delta_{4} \text { Post }_{t} * S C / S T_{i}+ \\
\delta_{5} \text { Treat }_{s} * S C / S T_{i}+\delta_{6} \text { Post }_{t} * \text { Treat }_{s} * S C / S T_{i}+\gamma_{1} X_{s t}+\gamma_{2} W_{i t}+\epsilon_{\text {sit }}
\end{gathered}
$$

where abbreviations are the same as those in equation (1). SC/ST is binary variable and captures whether child $i$ belong to SC/ST households. In Appendix Table A5 and A6, we report coefficient $\delta_{3}$, which gives the treatment effect for children from nonSC/ST households, and $\delta_{6}$, which gives the additional effect of the treatment for children from SC/ST households. $\delta_{6}$ is our main coefficient of interest. At the baseline, compared to non-SC/ST children, the anemia prevalence among SC/ST children is $3.5 \%$ percentage points higher $(44.1 \%$ vs. $47.6 \%)$. The prevalence of extreme form of anemia, mild/severe anemia, was $28.5 \%$ and $24.7 \%$ among SC/ST and non-SC/ST children, respectively.

\footnotetext{
${ }^{12}$ Scheduled caste and scheduled tribes (SC/ST) are historically disadvantages groups in India.
} 
We did not find statistically significant additional treatment effects for children from SC/ST households for the anemia outcomes, but the point estimates indicate that SC/ST households benefitted a little more (Table A5, column 2 and 3). Whereas the treatment reduced any form of anemia for a child from a non-SC/ST household by 8.5 percentage points, it additionally reduced any form of anemia among SC/ST children by 1.8 percentage points, though the point estimate is not statistically significant (column 2). Consistent with the insignificant effects on anemia, we did not find significantly larger impacts for SC/ST children on any measures of cognition or education (Appendix Table A6). The overall results indicate that the treatment effects are not disproportionately higher for SC/ST children compared with non-SC/ST children.

\section{Threats to internal validity}

\subsection{Partial compliance}

Compliance with the treatment might be disrupted due to non-usage, insufficient use of DFS, or insufficient availability of salt due to imperfect delivery channels. We believe that these issues are unlikely to have introduced bias because of the strong monitoring system that we had in place. The support of local authorities further strengthened the monitoring mechanism and reduced the possibility of partial compliance. Further, during a surprise visit to schools, we found DFS salt available in all treatment schools except for two; these schools had run out of DFS the day before the visit. Regarding the supply of DFS, very few schools reported having interrupted supply of DFS for more than five days during the treatment year.

Another potential source of bias could be resale of DFS to the control schools or households from the treatment schools. However, this is unlikely as the financial incentive of reselling DFS is very small since salt is a relatively inexpensive product. Furthermore, we know from anecdotal evidence that awareness of the benefits of DFS and the demand for it is very low, at least among the rural households in our study region. In the endline survey, a negligible proportion of 0.28 percent of the households reported having used DFS, indicating that the reselling of salt to households is an unlikely event. 
One could also imagine that the headmasters in the treatment schools sold DFS to control schools since headmasters in both control and treatment schools were informed of the study as part of their informed consent. The study informed headmasters in the treatment and control schools that a lottery would determine the treatment status of the schools. They were later informed of the results of the lottery. Headmasters were further informed that the local government supports the study and it is unlikely that they would have acted against the government order. Furthermore, headmasters in control schools were told that if the given study would yield positive results, they would also have the possibility to receive DFS. Lack of awareness about the availability and benefits of DFS among school headmasters would further reduce the bias if any existed. None of the control headmasters reported having used DFS in the preparation of the MDM. During the surprise visits, DFS was not found in any of the control schools. The order from the government to adhere to the study design and the incentive that control groups would have access to DFS after the completion of the study led to high compliance at the school level.

Non-compliance at the child level due to low school attendance has been discussed in section 5.2. Non-compliance at the child level could have potentially also occurred if the children that were enrolled in control schools at the baseline went to the treatment schools to receive the treatment and the other way around. This potential concern was circumvented in multiple ways. Firstly, only headmasters knew about the intervention. Anecdotal evidence further confirms that awareness of the benefits of DFS was very low, such that the incentive for parents to send their child to a treatment school to receive the DFS was non-existent. Additionally, every village generally is zoned to a specific public school, thus attending a school in another village is extremely uncommon and not feasible.

\subsection{Attenuation bias}

For ethical reasons, when conducting research with human subjects, especially with vulnerable populations such as children, it has to be ensured that the benefits of the research outweigh the risks (Medical Research Council 2004). To maximize the benefit for the children involved in the survey, both in the treatment as well as the control group, survey teams were instructed to inform parents if their child was moderately or severely anemic and to advise them to feed their children more diversely and to include more food items with high iron content (green leafy 
vegetables and meat in case they were non-vegetarians) in their diet. In cases of severe anemia, parents were instructed to consult a doctor (which was only the case for 14 children).

This additional intervention is unlikely to bias our results since this information intervention affected the treatment and control groups equally and its effect is therefore balanced between these two groups. However, in case the information intervention did indeed lead to a change in feeding practices or medical treatment, a saturation effect might have occurred (i.e. decreasing returns to scale of ironinterventions). Compared to an exclusive DFS intervention, the estimated coefficients in this study could, therefore, be downward biased and might constitute a lower bound. To address this potential threat we included the dietary diversity score of the child as a control variable in our main specification (1). In a companion analysis, we explored the effect of the nutrition information intervention with a regression discontinuity design and did not find an effect on any of the outcomes explored in this study, indicating that the nutrition information did not lead to attenuation bias (Krämer 2017).

\subsection{Hawthorne effect}

Another issue of concern may be Hawthorne effects, i.e. changes in the behavior of the individuals in the control group in response to being part of the DFS experiment. In our experiment individuals in the treatment and control groups were surveyed once at the baseline and once at the endline; any behavioral change that results from the survey itself (being monitored or the evaluation of the education level of the students) is balanced in the treatment and the control group. It might still have been the case that individuals in the treatment group changed their behavior due to the treatment itself (regular delivery of DFS to the school) and that this change affected the outcomes. Since only headmasters were aware of the intervention, this behavioral change is limited to headmasters (and maybe some teachers who knew about the intervention).

A change in hemoglobin values due to a behavioral change by the headmasters, for example spending more money on the MDM to improve dietary diversity, is very unlikely to have occurred since headmasters generally were unaware of the hemoglobin testing and also did not have a higher budget available. Nevertheless, we 
also control for the average calories and average iron content of the MDM as measured on the survey day. We also believe that the expected benefits of a behavioral change were too small in comparison to the effort needed to manipulate the outcomes. A change in the components of the MDM would involve additional costs and a change in cognitive or educational outcomes would need a large quality improvement in teaching (e.g. more teachers, more training material etc.). Therefore, we believe that the Hawthorne effect is less likely to be a concern in this study.

\section{Cost-effectiveness analysis}

We provide a couple of back of the envelope calculations to illustrate the costeffectiveness of the intervention, and to enable other researchers and policymakers to compare it with other micronutrient interventions. In total, we spent approximately INR 332,000 (4887 USD) on the one-year intervention. ${ }^{13}$ The cost of the intervention consists of the cost of the DFS subsidy (we received the DFS from the manufacturer for INR 20.04 per kilogram and provided it for INR 12 per kilogram to the headmasters, subsidy of $40 \%$ ) and the costs of delivering DFS to schools. The subsidy accounts for approximately INR 106,000 (1565 USD) and the distribution for approximately 226,000 INR (3322 USD). The intervention in the 54 schools reached almost 14,000 children (because all children at a school benefited from it and not only those that took part in the study), such that the cost per child was about INR 24, which is roughly equivalent to 0.36 USD. With an expenditure of slightly more than 100 USD, we provided DFS to about 300 children and, based on the estimated treatment effects in Table 2, 18 cases of anemia - six moderate or severe and twelve mild cases were averted. ${ }^{14}$ Applying the disability weights for mild (0.004) and moderate or severe (0.052) anemia this sums to 0.36 disability-adjusted-life-years (DALYs) averted (Murray and Lopez 2013). One DALY averted would, therefore, cost approximately 280 USD. The WHO assesses interventions as very cost-effective if the cost per DALY averted is less than the GNI per capita of the country where the intervention is going to be implemented, and cost-effective if it is less than three times

\footnotetext{
13 Average exchange rate in 2016. INR is the official currency of the Republic of India.

14 The point estimates of moderate and mild anemia add up to the point estimate of any anemia, which is statistically significant at the one percent level. Since disability weights only exist for moderate and severe anemia and not for any anemia, we take those point estimates although they have higher pvalues, which are likely a consequence of less power compared to the estimation with any anemia as outcome.
} 
the GNI per capita (Sachs 2001). India's GNI per capita at purchasing power parity in 2015 was 6,030 USD (World Bank 2017), which means that any intervention costing less than 6,030 USD per DALY averted would be considered very cost-effective under the WHO definition. This is true for the cost calculation of the intervention analyzed in this study. Our estimate is a very conservative assessment of the cost-effectiveness of the intervention because it ignores potential long-term effects of the intervention, effects on other outcomes such as education, and the possibility to benefit from economies of scale if included in existing distribution infrastructure.

\section{Conclusions}

We assessed the Indian MDM as a potential delivery channel to provide iron to second-grade primary school children to combat iron-deficient anemia. In a randomized controlled trial, we found that DFS provided through the MDM reduced the prevalence of any form of anemia by 20 percent and of mild anemia by 30 percent. For children that had a high school attendance (80 or 90 percent), and therefore ate the MDM more regularly, the treatment effect was also statistically significant for math and reading outcomes at a magnitude of close to 0.2 standard deviation increase. The intervention was very cost effective according to international standards.

The findings are particularly interesting in light of the results from Banerjee et al. (2018) study, which did not find any effect of DFS when sold at a subsidized price through local shops or the PDS system, or offered free to households. One central difference between the delivery channel of our study and the study by Banerjee et al. (2018) is that the DFS was mandatorily used in our study (at least by the children through the decision of their headmasters and the school authorities to participate in the study and use DFS for the mid-day meal), whereas in Banerjee et al. (2018) participation was voluntary and consumers were given the option to buy the fortified product or not. The positive effects from our study provide evidence of the potential advantage of mandatory fortification where a behavioral change in dietary patterns at the household level, which seemed to be a major challenge in the other studies, is not required.

There are some limitations to our study and potentials for further research. Firstly, 
since our results only apply to the two blocks in Bihar from which we have drawn a random sample of schools, we propose replications of this study in other contexts. In our supply system, a strong and trusting relationship between the headmasters and DFS distributors was maintained and the intervention was strongly supported by the local government, which might not be the case in a different context. Moreover, we would like to point to the duration of the intervention. Though we could not find statistically significant effects for the cognition outcomes and the only evidence for positive effects on educational outcomes showed up at higher levels of school attendance, it might very well be the case that these effects indeed exist but need longer time periods to materialize. Furthermore, it could also be the case that these children are deficient in multiple micronutrients (vitamin A, zinc etc.) and iron supplementation alone may not result in improved educational outcomes. Another reason for null effect on educational outcomes could be that lack of complementary school-level infrastructures and other supply-side bottlenecks may be holding back even the healthier children from realizing their full academic potential. We, therefore, believe that future studies should attempt to explore the longer-term effects of the DFS intervention alone, as well as of multiple micronutrient interventions with different variations in iron dosage and treatment duration. 


\section{References}

Andang'o, Pauline E. A, et al. "Efficacy of iron-fortified whole maize flour on iron status of schoolchildren in Kenya: a randomised controlled trial." The Lancet 369, no. 9575 (2007): 1799-1806.

Andersson, M., P. Thankachan, S. Muthayya, R. B. Goud, A. V. Kurpad, R. F. Hurrell, and M. B. Zimmermann. 2008. "Dual Fortifi cation of Salt with Iodine and Iron: A Randomized, Double- Blind, Controlled Trial of Micronized Ferric Pyrophosphate and Encapsulated Ferrous Fumarate in Southern India.” American Journal of Clinical Nutrition 88 (5): 1378-87. Anderson, P. "Assessment and Development of Executive Function (EF) During Childhood." Child Neuropsychology 8, no. 2 (2002): 71-82.

Anderson, V. "Assessing executive functions in children: biological, psychological, and developmental considerations." Pediatric Rehabilitation 4, no. 3 (2001): 119-136.

Ardila, Alfredo, Monica Rosselli, Esmeralda Matute, and Soledad Guajardo. "The morettiInfluence of the Parents' Educational Level on the Development of Executive Functions." Developmental Neuropsychology 28, no. 1 (2005): 539560.

ASER Centre. Annual Status of Education Report. ASER, 2014.

Ashraf, N, E Field, and J Lee. "Household Bargaining and Excess Fertility: An Experimental Study in Zambia." American Economic Review 104, no. 7 (2014): 2210-2237.

Baird, S, J. H Hicks, E Miguel, and M Kremer. "Worms at work: Long-run impacts of a child health investment." The Quarterly Journal of Economics 131, no. 4 (2016): 1637-1680.

Banerjee, A, S Barnhardt, and E Duflo. "Can Iron-Fortified Salt Control Anemia? Evidence from Two Experiments in Rural Bihar." Journal of Development Economics, 2018: 133:127-146.

Beard, J. "Iron deficiency alters brain development and functioning." The Journal of Nutrition 133, no. 5 (2003): 1468S-1472S.

Beard, J. L. "Why iron deficiency is important in infant development." The Journal of Nutrition 138, no. 12 (2008): 2534-2536. 
Berry, J., Mehta, S., Mukherjee, P., Ruebeck, H., Shastry, G.K., "Inputs, Monitoring, and Crowd-out in India's School-Based Health Interventions." Working paper (2017).

Bloom, D. E, D Canning, and D. T Jamison. "Health, Wealth and Welfare." Finance and Development 41, no. 1 (2004): 10-15.

Bobonis, G. J, E Miguel, and C Puri-Sharma. "Anemia and School Participation." The Journal of Human Resources 41, no. 1 (2006): 692-721.

Carlson, S. M. "Developmentally sensitive measures of executive function in preschool 168 children." Development neuropsychology 28, no. 2 (2005): 595616.

Carpenter, Patricia A, Marcel A Just, and Peter Shell. "What one intelligence test measures: a theoretical account of the processing in the Raven Progressive Matrices Test." Psychological Review, 1990: 404.

Chong, A., Cohen, I., Field, E., Nakasone, E., Torero, M., 2016. Iron deficiency and schooling attainment in Peru. Am. Econ. J. Appl. Econ, 8 (4), 2016, $222-$ 255 .

Currie, J, and T Vogl. "Early-life health and adult circumstance in developing countries." Annual Review of Economics 5, no. 1 (2013): 1-36.

Gerstadt, C. L, Y. J Hong, and A Diamond. "The relationship between cognition and action: performance of children 3 1/2-7 years old on a Stroop-like day-night test." Cognition 53, no. 2 (1994): 129-153.

Giovagnoli, A. R. "Relation of sorting impairment to hippocampal damage in temporal lobe epilepsy." Neuropsychologia 39, no. 2 (2001): 140-150.

Glewwe, P, M Kremer, and S Moulin. "Many children left behind? Textbooks and test scores in Kenya." American Economic Journal: Applied Economics 1, no. 1 (2009): 112-135.

Hale, J. B, J. A. B Hoeppner, and C. A Fiorello. "Analyzing digit span components for assessment of attention processes." Journal of Psychoeducational Assessment 20, no. 2 (2002): 128-143.

Halterman, J. S, J. M Kaczorowski, C. A Aligne, P Auinger, and P. G Szilagyi. "Iron deficiency and cognitive achievement among school-aged children and adolescents in the United States." Pediatrics 107, no. 6 (2001): 1381-1386.

Hudspeth, W. J, and K. H Pribram. "Stages of brain and cognitive maturation." Journal of Educational Psychology 82, no. 4 (1990): 881-884. 
International Institute for Population Sciences. National Family Health Survey 4. Mumbai: Government of India: Ministry of Health and Family Welfare, 2015.

Krämer, M. "Nutrition and Child Development in Low- and Middle-Income Countries - Evaluation of Three Micronutrient Interventions". University of Goettingen (2017). Available at http://hdl.handle.net/11858/00-1735-0000-0023-3EA5-C

Kretchmer, N, J. L Beard, and S Carlson. "The role of nutrition in the development of normal cognition." American Journal of Clinical Nutrition 63, no. 6 (1996).

Leeds, L. "A comparison of the new executive functioning domains of the CAMCOG-R with existing tests of executive function in elderly stroke survivors." Age and ageing 30, no. 3 (2001): 251-254.

Lezak, M. D. Neuropsychological assessment. 3. Oxford: Oxford University Press, 1995.

Lozoff, B, N. K Klein, E. C Nelson, D. K McClish, M Manuel, and M. E Chacon. "Behavior of infants with iron-deficiency anemia." Child Development 69, no. 1 (1998): 24-36.

Malin, A. J. "Malin's intelligence scale for Indian children." Nagpur (India): Child Guidance Center, 1969.

Maluccio, John A, John Hoddinott, Jere R Behrman, Reynaldo Martorell, Agnes R Quisumbing, and Aryeh D Stein. "The Impact of Improving Nutrition During Early Childhood on Education among Guatemalan Adults." The Economic Journal 119, no. 537 (2009): 734-763.

Medical Research Council. MRC Ethics Guide: Medical Research involving Children. MRC, 2004.

Ministry of Human Resource Development, About MDM. 2016. http://mdm.nic.in/.

Moretti, D, et al. "Extruded rice fortified with micronized ground ferric pyrophosphate reduces iron deficiency in Indian schoolchildren: a doubleblind randomized controlled trial." The American Journal of Clinical Nutrition 84, no. 4 (2006): 822-829.

Mudur, G. S. Doubts on fortified midday-meal salt - safe but no clear proof it increases haemoglobin: Scientists. The Telegraph India, 2013.

Murray, C. J. L, and A. D Lopez. "Measuring the Global Burden of Disease." New England Journal of Medicine 369, no. 5 (2013): 448-457. 
Nair, S, R Goswami, M. G. R Rajan, and V Thakkar. "Impact of double fortified salt on iron and iodine deficient school children (6 to 12 years) of rural Vadodara." Journal of Public Health and Epidemiology 5, no. 9 (2013): 370-373.

Radhika, M, et al. "Micronized ferric pyrophosphate supplied through extruded rice kernels improves body iron stores in children: a double-blind, randomized, placebo-controlled midday meal feeding trial in Indian schoolchildren." American Journal of Clinical Nutrition 94, no. 5 (2011): 1202-1210.

Raven, John C, and John H Court. Raven's progressive matrices and vocabulary scales. Oxford: Oxford Psychologists Press Oxford, 1998.

Sachs, J. D. "Macroeconomics and Health: Investing in Health for Economic Development: Report of the Commission on Macroeconomics and Health." Nature Medicine 8, no. 6 (2001): 1-200.

Salimpoor, V. N, and M Desrocher. "Increasing the utility of EF assessment of executive function in children." Developmental Disabilities Bulletin, 2006: 1542.

Sivakumar, B, et al. "Prospects of fortification of salt with iron and iodine." British Journal of Nutrition 85, no. 2 (2001): 167.

Thomas, D., E. Frankenberg, J. Friedman, J.-P. Habicht, M. Hakimi, N. Ingwersen, N. Jones, C. McKelvey, G. Pelto, B. Sikoki, et al. Causal effect of health on labor market outcomes: Experimental evidence. California Center for Population Research, Working Paper Series CCPR-070-06, University of California, Los Angeles.

Thatcher, R. W. "Maturation of the human frontal lobes: Physiological evidence for staging." Developmental Neuropsychology 7, no. 3 (1991): 397-419.

van Stuijvenberg, M. E. "Using the School Feeding System as a Vehicle for Micronutrient Fortification: Experience from South Africa." Food and Nutrition Bulletin 26 (2005): S213-S219.

World Bank. "World Development Indicators." 2017.

World Health Organization. Haemoglobin concentrations for the diagnosis of anaemia and assessment. Geneva: World Health Organization, 2011.

World Health Organization. Iron deficiency aneamia: report of a study group. Geneva: World Health Organization, 1959.

World Health Organization. Worldwide prevalence of anaemia 1993-2005. WHO Global Database on Anaemia, 2008. 
Zimmermann, M. B, C Zeder, N Chaouki, A Saad, T Torresani, and R. F Hurrell.

"Dual fortification of salt with iodine and microencapsulated iron: a randomized, double-blind, controlled trial in Moroccan school children." The American Journal of Clinical Nutrition 77, no. 2 (2003): 425-432. 
Table 1: Baseline summary statistics (Balance checks)

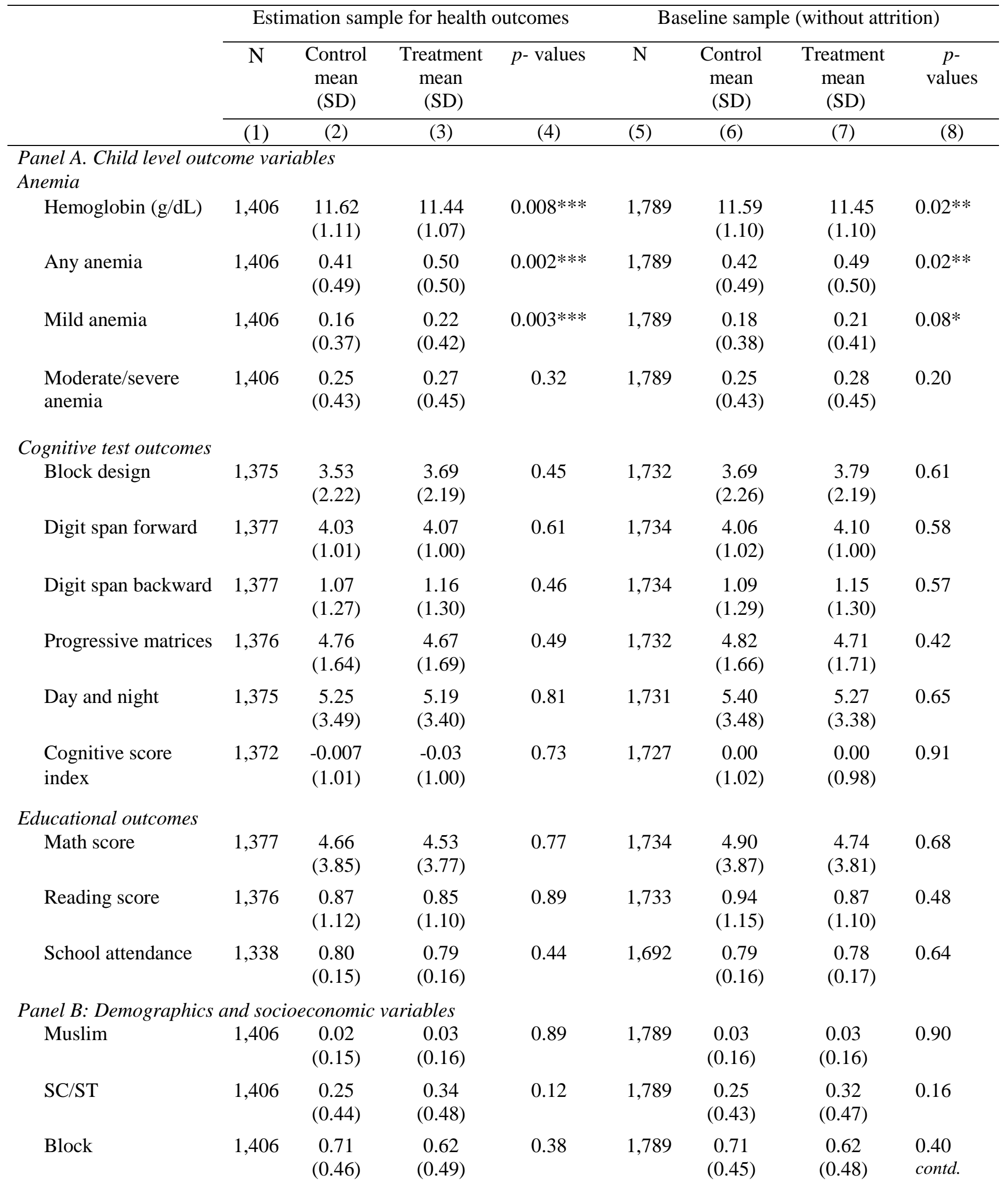




\begin{tabular}{|c|c|c|c|c|c|c|c|c|}
\hline Rural & 1,406 & $\begin{array}{c}0.97 \\
(0.16)\end{array}$ & $\begin{array}{c}0.98 \\
(0.13)\end{array}$ & 0.59 & 1,789 & $\begin{array}{c}0.97 \\
(0.16)\end{array}$ & $\begin{array}{c}0.99 \\
(0.12)\end{array}$ & 0.42 \\
\hline Family size & 1,406 & $\begin{array}{c}7.85 \\
(3.47)\end{array}$ & $\begin{array}{c}7.62 \\
(3.29)\end{array}$ & 0.31 & 1,789 & $\begin{array}{c}7.85 \\
(3.53)\end{array}$ & $\begin{array}{l}7.66 \\
(3.35)\end{array}$ & 0.39 \\
\hline $\begin{array}{l}\text { Father's years of } \\
\text { schooling }\end{array}$ & 1,406 & $\begin{array}{c}5.48 \\
(4.76)\end{array}$ & $\begin{array}{c}5.29 \\
(4.81)\end{array}$ & 0.63 & 1,789 & $\begin{array}{c}5.43 \\
(4.85)\end{array}$ & $\begin{array}{c}5.56 \\
(4.89)\end{array}$ & 0.73 \\
\hline $\begin{array}{l}\text { Mother's years of } \\
\text { schooling }\end{array}$ & 1,406 & $\begin{array}{l}1.70 \\
(3.15)\end{array}$ & $\begin{array}{l}1.58 \\
(2.94)\end{array}$ & 0.60 & 1,789 & $\begin{array}{c}1.81 \\
(3.27)\end{array}$ & $\begin{array}{l}1.80 \\
(3.22)\end{array}$ & 0.96 \\
\hline Asset index & 1,406 & $\begin{array}{c}0.01 \\
(0.95)\end{array}$ & $\begin{array}{l}-0.01 \\
(1.04)\end{array}$ & 0.82 & 1,789 & $\begin{array}{l}-0.03 \\
(0.95)\end{array}$ & $\begin{array}{l}-0.02 \\
(1.00)\end{array}$ & 0.92 \\
\hline Gender of the child & 1,406 & $\begin{array}{c}0.44 \\
(0.50)\end{array}$ & $\begin{array}{c}0.46 \\
(0.50)\end{array}$ & 0.43 & 1,789 & $\begin{array}{l}0.45 \\
(0.50)\end{array}$ & $\begin{array}{c}0.47 \\
(0.50)\end{array}$ & 0.39 \\
\hline \multicolumn{9}{|l|}{ Health care } \\
\hline $\begin{array}{l}\text { Institutional } \\
\text { delivery }\end{array}$ & 1,406 & $\begin{array}{c}0.40 \\
(0.49)\end{array}$ & $\begin{array}{c}0.37 \\
(0.48)\end{array}$ & 0.42 & 1,789 & $\begin{array}{c}0.39 \\
(0.49)\end{array}$ & $\begin{array}{c}0.38 \\
(0.49)\end{array}$ & 0.64 \\
\hline Health insurance & 1,406 & $\begin{array}{c}0.40 \\
(0.49)\end{array}$ & $\begin{array}{c}0.37 \\
(0.48)\end{array}$ & 0.54 & 1,789 & $\begin{array}{c}0.40 \\
(0.49)\end{array}$ & $\begin{array}{c}0.38 \\
(0.49)\end{array}$ & 0.69 \\
\hline Diarrhea & 1,406 & $\begin{array}{c}0.04 \\
(0.20)\end{array}$ & $\begin{array}{c}0.03 \\
(0.16)\end{array}$ & 0.30 & 1,789 & $\begin{array}{c}0.03 \\
(0.18)\end{array}$ & $\begin{array}{c}0.03 \\
(0.17)\end{array}$ & 0.57 \\
\hline Improved sanitation & 1,406 & $\begin{array}{c}0.07 \\
(0.25)\end{array}$ & $\begin{array}{c}0.08 \\
(0.27)\end{array}$ & 0.56 & 1,789 & $\begin{array}{c}0.08 \\
(0.27)\end{array}$ & $\begin{array}{c}0.09 \\
(0.29)\end{array}$ & 0.53 \\
\hline \multicolumn{9}{|l|}{ Jutrition } \\
\hline Diet diversity score & 1,406 & $\begin{array}{c}3.90 \\
(1.18)\end{array}$ & $\begin{array}{c}3.83 \\
(1.15)\end{array}$ & 0.45 & 1,789 & $\begin{array}{c}3.90 \\
(1.19)\end{array}$ & $\begin{array}{c}3.86 \\
(1.14)\end{array}$ & 0.66 \\
\hline $\begin{array}{l}\text { Number of } \\
\text { meals/day }\end{array}$ & 1,406 & $\begin{array}{c}3.04 \\
(1.06)\end{array}$ & $\begin{array}{c}3.07 \\
(1.01)\end{array}$ & 0.77 & 1,789 & $\begin{array}{c}3.01 \\
(1.07)\end{array}$ & $\begin{array}{c}3.04 \\
(1.03)\end{array}$ & 0.65 \\
\hline Food scarcity & 1,406 & $\begin{array}{c}0.82 \\
(0.39)\end{array}$ & $\begin{array}{c}0.81 \\
(0.39)\end{array}$ & 0.74 & 1,789 & $\begin{array}{c}0.80 \\
(0.40)\end{array}$ & $\begin{array}{c}0.80 \\
(0.40)\end{array}$ & 0.81 \\
\hline $\begin{array}{l}\text { Maternal health } \\
\text { knowledge }\end{array}$ & 1,406 & $\begin{array}{c}0.35 \\
(0.48)\end{array}$ & $\begin{array}{c}0.38 \\
(0.49)\end{array}$ & 0.42 & 1,789 & $\begin{array}{c}0.36 \\
(0.48)\end{array}$ & $\begin{array}{c}0.40 \\
(0.49)\end{array}$ & 0.19 \\
\hline $\begin{array}{l}\text { Child eats meat } \\
\text { products }\end{array}$ & 1,406 & $\begin{array}{c}0.55 \\
(0.50)\end{array}$ & $\begin{array}{c}0.52 \\
(0.50)\end{array}$ & 0.45 & 1,789 & $\begin{array}{c}0.53 \\
(0.50)\end{array}$ & $\begin{array}{c}0.53 \\
(0.50)\end{array}$ & 0.87 \\
\hline $\begin{array}{l}\text { Child received iron } \\
\text { supplements }\end{array}$ & 1,406 & $\begin{array}{c}0.16 \\
(0.37)\end{array}$ & $\begin{array}{c}0.17 \\
(0.38)\end{array}$ & 0.63 & 1,789 & $\begin{array}{c}0.17 \\
(0.38)\end{array}$ & $\begin{array}{c}0.17 \\
(0.37)\end{array}$ & 0.92 \\
\hline \multicolumn{9}{|c|}{ anel C: School level covariates } \\
\hline $\begin{array}{l}\text { Calories of MDM } \\
\text { per child }\end{array}$ & 107 & $\begin{array}{l}69.57 \\
(21.45)\end{array}$ & $\begin{array}{c}68.04 \\
(25.62)\end{array}$ & 0.74 & 107 & $\begin{array}{l}69.57 \\
(21.45)\end{array}$ & $\begin{array}{c}68.04 \\
(25.62)\end{array}$ & 0.74 \\
\hline $\begin{array}{l}\text { Amount of iron in } \\
\text { MDM per child } \\
(\mathrm{mg})\end{array}$ & 107 & $\begin{array}{c}0.84 \\
(0.41)\end{array}$ & $\begin{array}{c}0.75 \\
(0.28)\end{array}$ & 0.19 & 107 & $\begin{array}{c}0.84 \\
(0.41)\end{array}$ & $\begin{array}{c}0.75 \\
(0.28)\end{array}$ & 0.19 \\
\hline
\end{tabular}

Notes: This tables presents summary statistics as well as p-values for difference in the means t-tests between children in the treatment and the control schools. All variables shown are child level variables from the baseline except for panel C, which shows school level variables. SD: Standard deviation, MDM: Mid-day meal; SC/ST: Scheduled caste/scheduled tribe are the social and economically disadvantaged groups; N: Number of observations. 
Table 2: ITT effects of the DFS treatment on hemoglobin level and anemia

\begin{tabular}{|c|c|c|c|c|}
\hline & Hemoglobin & $\begin{array}{l}\text { Any } \\
\text { anemia }\end{array}$ & $\begin{array}{l}\text { Mild } \\
\text { anemia }\end{array}$ & $\begin{array}{l}\text { Moderate } \\
\text { or severe } \\
\text { anemia }\end{array}$ \\
\hline & (1) & (2) & (3) & (4) \\
\hline \multirow[t]{2}{*}{ Treatment } & $0.136^{*}$ & $-0.093 * * *$ & $-0.060 * *$ & -0.034 \\
\hline & $(0.076)$ & $(0.033)$ & $(0.027)$ & $(0.031)$ \\
\hline Mean of dependent variable & 11.529 & 0.452 & 0.193 & 0.260 \\
\hline Child fixed effects & Yes & Yes & Yes & Yes \\
\hline Controls & Yes & Yes & Yes & Yes \\
\hline Observations & 2,812 & 2,812 & 2,812 & 2,812 \\
\hline $\begin{array}{l}\text { Notes: Estimated coefficients are } \\
\text { anemia is defined as a hemoglobi } \\
\&<11.5 \mathrm{~g} / \mathrm{dl} \text {, moderate } / \mathrm{severe} a \\
\text { significance at the } 10 \%, 5 \% \text { and } \\
\text { are reported in parentheses. }\end{array}$ & $\begin{array}{l}\text { sed on a DID r } \\
\text { ue }<11.5 \mathrm{~g} / \mathrm{dl} \text {, }\end{array}$ & del estimatec & $\begin{array}{l}\text { parately in } \\
\text { hed as a hem } \\
\text { e }<11 \mathrm{~g} / \mathrm{dl} \\
\text { s, clustered }\end{array}$ & $\begin{array}{l}\text { column. An } \\
\text { bin value } \geq 1 \\
k *, * * * \text { denot } \\
\text { e school level }\end{array}$ \\
\hline
\end{tabular}


Table 3: ITT effects of the DFS treatment on cognition and education

\begin{tabular}{|c|c|c|c|c|c|c|}
\hline & $\begin{array}{l}\text { Block } \\
\text { design }\end{array}$ & $\begin{array}{l}\text { Digit } \\
\text { span } \\
\text { forward }\end{array}$ & $\begin{array}{l}\text { Digit } \\
\text { span } \\
\text { backward }\end{array}$ & $\begin{array}{l}\text { Progressive } \\
\text { matrices }\end{array}$ & $\begin{array}{l}\text { Day and } \\
\text { night }\end{array}$ & $\begin{array}{l}\text { Cognitive } \\
\text { Index }\end{array}$ \\
\hline & $(1)$ & $(2)$ & $(3)$ & (4) & $(5)$ & (6) \\
\hline \multicolumn{7}{|l|}{ Panel A } \\
\hline Treatment & $\begin{array}{l}0.012 \\
(0.082)\end{array}$ & $\begin{array}{l}-0.105 \\
(0.074)\end{array}$ & $\begin{array}{l}0.009 \\
(0.084)\end{array}$ & $\begin{array}{l}0.070 \\
(0.095)\end{array}$ & $\begin{array}{l}0.116 \\
(0.098)\end{array}$ & $\begin{array}{l}0.028 \\
(0.080)\end{array}$ \\
\hline $\begin{array}{l}\text { Mean of dependent } \\
\text { variable }\end{array}$ & 0.048 & 0.030 & 0.033 & -0.020 & 0.000 & -0.038 \\
\hline Child fixed-effects & Yes & Yes & Yes & Yes & Yes & Yes \\
\hline Controls & Yes & Yes & Yes & Yes & Yes & Yes \\
\hline Observations & 2,790 & 2,790 & 2,790 & 2,790 & 2,790 & 2,790 \\
\hline \multicolumn{7}{|l|}{ Panel B } \\
\hline & \multicolumn{2}{|c|}{$\begin{array}{l}\text { Math } \\
\text { (1) }\end{array}$} & \multicolumn{2}{|c|}{$\begin{array}{l}\text { Reading } \\
\text { (2) }\end{array}$} & \multicolumn{2}{|c|}{$\begin{array}{l}\text { School attendance } \\
\text { (3) }\end{array}$} \\
\hline Treatment & \multicolumn{2}{|c|}{$\begin{array}{c}0.129 \\
(0.090)\end{array}$} & \multicolumn{2}{|c|}{$\begin{array}{c}0.104 \\
(0.081)\end{array}$} & & $\begin{array}{l}05 \\
22)\end{array}$ \\
\hline $\begin{array}{l}\text { Mean of dependent } \\
\text { variable }\end{array}$ & \multicolumn{2}{|c|}{-0.007} & \multicolumn{2}{|c|}{-0.019} & & 98 \\
\hline Child fixed-effects & \multicolumn{2}{|c|}{ Yes } & \multicolumn{2}{|c|}{ Yes } & \multicolumn{2}{|c|}{ Yes } \\
\hline Controls & \multicolumn{2}{|c|}{ Yes } & \multicolumn{2}{|c|}{ Yes } & \multicolumn{2}{|c|}{ Yes } \\
\hline Observations & \multicolumn{2}{|c|}{2,790} & \multicolumn{2}{|c|}{2,790} & \multicolumn{2}{|c|}{2,715} \\
\hline
\end{tabular}

Notes: Estimated coefficients are based on a DID model estimated separately in each column. All outcomes, except school attendance, are normalized with reference to the baseline mean in the control group. *, **,*** denote significance at the $10 \%, 5 \%$ and $1 \%$ levels, respectively. Standard errors, clustered at the school level, are reported in parentheses. 
Table 4: Heterogeneous treatment effects on hemoglobin and anemia by school attendance rate

\begin{tabular}{lcccc}
\hline & Hemoglobin & $\begin{array}{c}\text { Any } \\
\text { anemia }\end{array}$ & $\begin{array}{c}\text { Mild } \\
\text { anemia }\end{array}$ & $\begin{array}{c}\text { Moderate or } \\
\text { severe anemia }\end{array}$ \\
\cline { 2 - 5 } & $(1)$ & $(2)$ & $(3)$ & $(4)$ \\
\hline Treat (70\% attendance) & $0.138^{*}$ & $-0.089^{* * *}$ & $-0.060^{* *}$ & -0.029 \\
& $(0.075)$ & $(0.032)$ & $(0.027)$ & $(0.031)$ \\
Treat (80\% attendance) & 0.144 & $-0.093^{* *}$ & $-0.058^{*}$ & -0.036 \\
& $(0.089)$ & $(0.039)$ & $(0.030)$ & $(0.034)$ \\
Treat (90\% attendance) & 0.151 & $-0.098^{*}$ & -0.056 & -0.042 \\
& $(0.113)$ & $(0.051)$ & $(0.039)$ & $(0.042)$ \\
Mean of dependent & 11.530 & 0.451 & 0.191 & 0.260 \\
variable & & & & \\
Child fixed-effects & Yes & Yes & Yes & Yes \\
Controls & Yes & Yes & Yes & Yes \\
Observations & 2,780 & 2,780 & 2,780 & 2,780 \\
\hline $\begin{array}{l}\text { Notes: Standard errors, clustered at the school level, are reported in parentheses. All coefficients are from a } \\
\text { separate regression, except for the last coefficients that are from one regression where treatment and }\end{array}$ \\
attendance are interacted. Any anemia is defined as a hemoglobin value < 11.5 g/dl, mild anemia is defined \\
as a hemoglobin value $\geq 11 \&<11.5$ g/dl, moderate/severe anemia is defined as a hemoglobin value < 11 \\
g/dl. *,**,*** denote significance at the 10\%, 5\% and 1\% level, respectively.
\end{tabular}


Table 5: Heterogeneous treatment effects on cognition and education by school attendance rate

\begin{tabular}{|c|c|c|c|c|c|c|c|c|}
\hline & $\begin{array}{l}\text { Block } \\
\text { design }\end{array}$ & $\begin{array}{l}\text { Digit span } \\
\text { forward }\end{array}$ & $\begin{array}{l}\text { Digit span } \\
\text { backward }\end{array}$ & $\begin{array}{l}\text { Progressive } \\
\text { matrices }\end{array}$ & $\begin{array}{l}\text { Day and } \\
\text { night }\end{array}$ & $\begin{array}{l}\text { Cognitive } \\
\text { Index }\end{array}$ & $\begin{array}{l}\text { Math test } \\
\text { score }\end{array}$ & $\begin{array}{l}\text { Reading } \\
\text { test score }\end{array}$ \\
\hline & (1) & (2) & (3) & (4) & (5) & (6) & (7) & (8) \\
\hline Treat (70\% attendance) & $\begin{array}{l}0.005 \\
(0.081)\end{array}$ & $\begin{array}{l}-0.117 \\
(0.073)\end{array}$ & $\begin{array}{l}0.001 \\
(0.090)\end{array}$ & $\begin{array}{l}0.065 \\
(0.099)\end{array}$ & $\begin{array}{l}0.109 \\
(0.100)\end{array}$ & $\begin{array}{l}0.017 \\
(0.083)\end{array}$ & $\begin{array}{l}0.124 \\
(0.088)\end{array}$ & $\begin{array}{l}0.096 \\
(0.081)\end{array}$ \\
\hline Treat ( $80 \%$ attendance) & $\begin{array}{l}0.025 \\
(0.086)\end{array}$ & $\begin{array}{l}-0.128 \\
(0.081)\end{array}$ & $\begin{array}{l}-0.011 \\
(0.084)\end{array}$ & $\begin{array}{l}0.089 \\
(0.097)\end{array}$ & $\begin{array}{l}0.160 \\
(0.102)\end{array}$ & $\begin{array}{l}0.038 \\
(0.084)\end{array}$ & $\begin{array}{l}0.161 * \\
(0.092)\end{array}$ & $\begin{array}{l}0.139 \\
(0.087)\end{array}$ \\
\hline Treat (90\% attendance) & $\begin{array}{l}0.045 \\
(0.104)\end{array}$ & $\begin{array}{l}-0.139 \\
(0.099)\end{array}$ & $\begin{array}{l}-0.023 \\
(0.095)\end{array}$ & $\begin{array}{l}0.112 \\
(0.110)\end{array}$ & $\begin{array}{l}0.210 \\
(0.114)\end{array}$ & $\begin{array}{l}0.058 \\
(0.096)\end{array}$ & $\begin{array}{l}0.197 * \\
(0.105)\end{array}$ & $\begin{array}{l}0.182 * \\
(0.104)\end{array}$ \\
\hline $\begin{array}{l}\text { Mean of dependent } \\
\text { variable }\end{array}$ & 0.049 & 0.035 & 0.036 & -0.023 & -0.002 & -0.039 & -0.008 & -0.019 \\
\hline Child fixed-effects & Yes & Yes & Yes & Yes & Yes & Yes & Yes & Yes \\
\hline Controls & Yes & Yes & Yes & Yes & Yes & Yes & Yes & Yes \\
\hline Observations & 2,766 & 2,766 & 2,766 & 2,766 & 2,766 & 2,766 & 2,766 & 2,766 \\
\hline
\end{tabular}


Figure 1: Distribution of school attendance during the treatment period ( 0 to $100 \%$ )

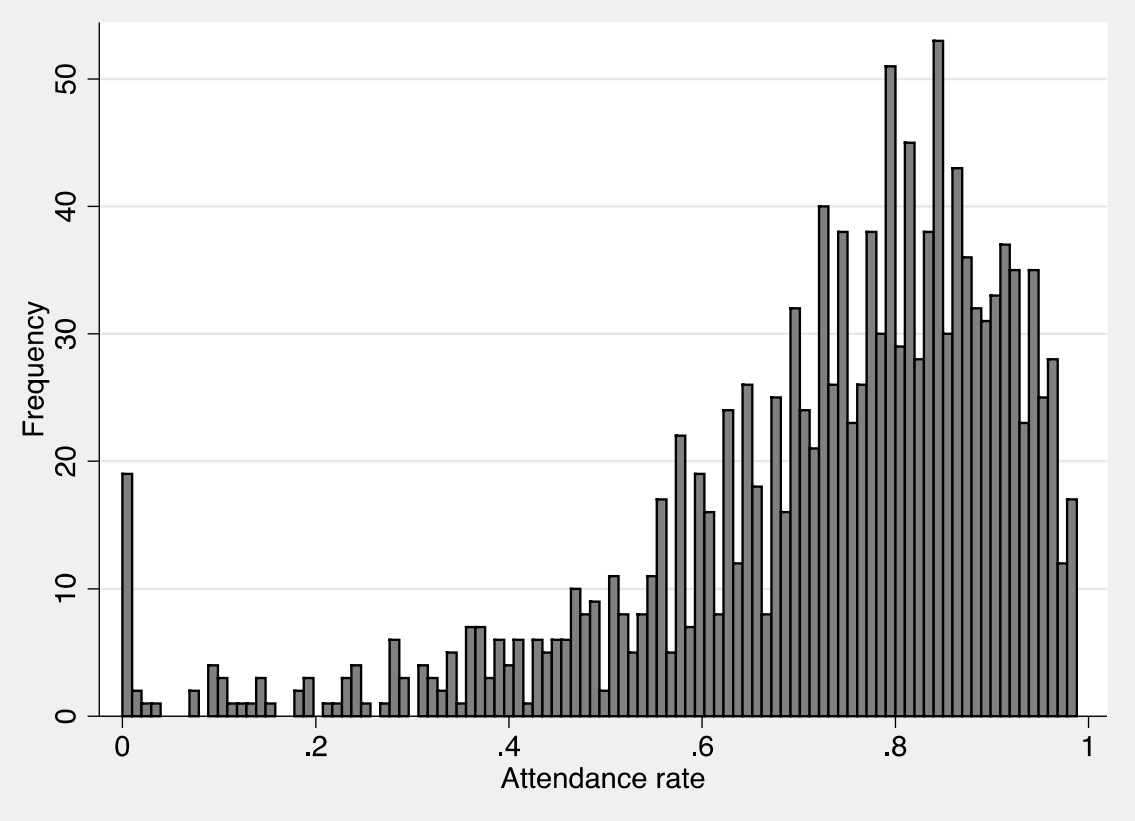




\section{A. Appendix}

\section{Indicators for cognitive ability}

The forward digit-span assesses short-term auditory memory and simple verbal expression (Hale, Hoeppner and Fiorello 2002). It is the only test that does not directly involve executive functions. The child was asked to repeat a series of numbers immediately after the enumerator read the series. The number of digits continuously increased and the longest list of numbers that the child could remember is defined as the digit-span.

The backward digit-span test measures the ability to store, use and manipulate new information. Backward digit-span also involves attention, impulse control and shifting from a forward to backward sequence. These abilities are commonly considered to be a part of the group of executive functions (Carlson 2005, Hale, Hoeppner and Fiorello 2002, Lezak 1995). The administration of the backward digit-span test is the same as in forward digit-span test, however the child is requested to repeat the digit sequence in its reverse order.

The Block design test assesses planning and organizing (V. Anderson 2001). In this test, children were asked to arrange red and white colored blocks in a way that they match the pattern of a picture. Children received two points if they correctly arranged the blocks on the first try, one point if they correctly arranged the blocks on the second try after the test administrator had shown the correct solution to the child, and zero otherwise. They were asked to arrange four different pictures in the baseline survey, each increasing in difficulty. To account for a general increase in cognitive ability at the endline survey, two more pictures were added.

The Stroop-like day-and-night test (Gerstadt, Hong and Diamond 1994) assesses the ability of inhibition (suppressing a habitual response), which is also considered to be a classical executive function (V. Anderson 2001, Carlson 2005). We used an extended version of this test, where six pairs of cards that show pictures of opposites (daynight, boy-girl, large-small, up-down, warm-cold and young-old) were presented to the child. After shuffling the pictures, they were presented to the child one after the other and the child was asked to say the opposite of what they were seeing on the card. The scale for the day-and-night test ranges from 0 to 12. Initial errors that were self-corrected by the child were scored as a half point. Apart from inhibition, this test also requires memorizing two rules simultaneously. Firstly what the picture on the cards represents, and secondly to always say the opposite.

Lastly, we used an abbreviated version of Raven's Colored Progressive Matrices (RCPM) (Raven and Court 1998) that measures abstract reasoning and the capacity to simultaneously solve several problems involving new information (Carpenter, Just and Shell 1990). There is some debate as to what extent the RCPM test measures executive functions (Ardila, et al. 2005, Giovagnoli 2001, Leeds 2001). In this test, 
the child was shown an array of pictures with one missing box. Out of the six options, they were to select the picture that fits the missing box. The pictures progressively increased in complexity and abstraction. We score each correct answer with one point, hence the scale for RCPM ranges from 0 to 12. The RCPM are designed for children between 5 and 11 years old.

Since the unit in which cognitive ability is measured is arbitrary, we normalized the test scores of the five cognitive tests and express it in z-scores. We calculated a cognitive index out of the five cognitive tests by using principal component analysis.

Table A1: Cognitive tests

\begin{tabular}{|c|c|c|c|}
\hline Test & Original Source & Cognitive ability & $\begin{array}{l}\text { Executive } \\
\text { function }\end{array}$ \\
\hline Digit span forwards & $\begin{array}{l}\text { Malin's Intelligence } \\
\text { Scale for Indian } \\
\text { Children }\end{array}$ & $\begin{array}{l}\text { - Short-term auditory } \\
\text { memory } \\
\text { - Simple verbal expression }\end{array}$ & \\
\hline Digit span backwards & $\begin{array}{l}\text { Malin's Intelligence } \\
\text { Scale for Indian } \\
\text { Children }\end{array}$ & $\begin{array}{l}\text { - Store, use and manipulate } \\
\text { new information } \\
\text { - Attention } \\
\text { - Impulse control } \\
\text { - Shifting }\end{array}$ & $\mathrm{x}$ \\
\hline Block design & $\begin{array}{l}\text { Malin's Intelligence } \\
\text { Scale for Indian } \\
\text { Children }\end{array}$ & - Planning and organizing & $\mathrm{X}$ \\
\hline $\begin{array}{l}\text { Stroop-like day and } \\
\text { night test }\end{array}$ & Gerstadt et al. (1994) & $\begin{array}{l}\text { - Inhibition } \\
\text { - Memorizing two rules } \\
\text { simultaneously }\end{array}$ & $\mathrm{x}$ \\
\hline $\begin{array}{l}\text { Raven's colored } \\
\text { progressive matrices }\end{array}$ & Raven et al. (1998) & $\begin{array}{l}\text { - Abstract reasoning } \\
\text { - Capacity to simultaneously } \\
\text { solve several problems } \\
\text { involving new information }\end{array}$ & $\mathrm{x}$ \\
\hline
\end{tabular}


Table A2: MDE for different outcomes and different \% of take-up

\begin{tabular}{|c|c|c|c|c|c|}
\hline & SD & $\begin{array}{l}\text { Baseline } \\
\text { ICC }\end{array}$ & $\begin{array}{l}\text { MDE } \quad(\mathrm{c}= \\
0.7)\end{array}$ & $\begin{array}{l}\text { MDE } \quad(\mathrm{c}= \\
0.8)\end{array}$ & $\begin{array}{l}\text { MDE } \quad(\mathrm{c}= \\
0.9)\end{array}$ \\
\hline \multicolumn{6}{|l|}{ Anemia } \\
\hline Hemoglobin & 1.10342 & 0.03130 & 0.23313 & 0.20399 & 0.18132 \\
\hline Any anemia & 0.49803 & 0.02208 & 0.09889 & 0.08653 & 0.07691 \\
\hline Mild anemia & 0.39225 & 0.00000 & 0.06438 & 0.05633 & 0.05007 \\
\hline Moderate anemia & 0.43686 & 0.02087 & 0.08599 & 0.07524 & 0.06688 \\
\hline Severe anemia & 0.08848 & 0.00000 & 0.01452 & 0.01271 & 0.01129 \\
\hline $\mathrm{N}$ anemia symptoms & 1.09933 & 0.08387 & 0.29981 & 0.26233 & 0.23318 \\
\hline Perceived child health & 0.40007 & 0.09271 & 0.11272 & 0.09863 & 0.08767 \\
\hline \multicolumn{6}{|l|}{$\begin{array}{l}\text { Cognition } \\
\text { education }\end{array}$} \\
\hline Block design & 0.98478 & 0.13069 & 0.31275 & 0.27366 & 0.24325 \\
\hline Digit span forwards & 0.98601 & 0.06170 & 0.24519 & 0.21454 & 0.19070 \\
\hline Digit span backwards & 1.00564 & 0.10957 & 0.29987 & 0.26239 & 0.23323 \\
\hline Progressive Matrices & 1.01746 & 0.11758 & 0.31103 & 0.27215 & 0.24191 \\
\hline Day and night & 0.98825 & 0.09899 & 0.28460 & 0.24902 & 0.22135 \\
\hline \multicolumn{6}{|l|}{ Education } \\
\hline Math & 0.98212 & 0.13875 & 0.31888 & 0.27902 & 0.24802 \\
\hline Reading & 0.99259 & 0.20815 & 0.37754 & 0.33035 & 0.29364 \\
\hline School attendance & 0.17110 & 0.19551 & 0.06345 & 0.05552 & 0.04935 \\
\hline \multicolumn{6}{|c|}{$\begin{array}{l}\text { SD: Standard deviation. ICC: Inter-cluster correlation. MDE: Minimal detectable effect. c: Take-up } \\
\text { rate. Assumptions: Sample size per cluster 22, number of clusters: } 108 \mathrm{schools,} \mathrm{division} \mathrm{of} \\
\text { observations between treatment and control: } 50: 50 \text {. Hemoglobin is expressed in } \mathrm{g} / \mathrm{dl} \text { and the different } \\
\text { forms of anemia represent percentage points). Cognitive and education outcomes are normalized with } \\
\text { respect to the control group mean and standard deviation. }\end{array}$} \\
\hline
\end{tabular}

Table A3: Correlation between attrition and treatment status

\begin{tabular}{lccc}
\hline & Anemia Sample & $\begin{array}{c}\text { Cognitive and } \\
\text { education sample }\end{array}$ & Attendance sample \\
\cline { 2 - 4 } & $(1)$ & $(2)$ & $(3)$ \\
\hline Treatment & -0.024 & -0.037 & -0.042 \\
& $(0.028)$ & $(0.030)$ & $(0.031)$ \\
& 1,791 & 1,772 & 1.713 \\
\hline Observations & Notes: All estimates are based on OLS regression where treatment status is regressed on attrition. *, **, \\
*** denote statistical significance at the $10 \%, 5 \%$, and $1 \%$ level, respectively.
\end{tabular}


Table A4: Baseline summary statistics for education sample (balance check)

\begin{tabular}{cccccccc}
\multicolumn{2}{c}{ Estimation sample for health outcomes } & \multicolumn{3}{c}{ Baseline sample (without attrition) } \\
\hline $\mathrm{N}$ & Control & Treatment & $p$-values & $\mathrm{N}$ & Control & Treatment & $p$ - \\
& mean & mean & & & mean & mean & values \\
& $(\mathrm{SD})$ & $(\mathrm{SD})$ & & & $(\mathrm{SD})$ & $(\mathrm{SD})$ & \\
\hline$(1)$ & $(2)$ & $(3)$ & $(4)$ & $(5)$ & $(6)$ & $(7)$ & $(8)$
\end{tabular}

Panel A. Child level outcome variables

Anemia

\begin{tabular}{|c|c|c|c|c|c|c|c|c|}
\hline Hemoglobin (g/dL) & 1,368 & $\begin{array}{l}11.62 \\
(1.10)\end{array}$ & $\begin{array}{l}11.42 \\
(1.10)\end{array}$ & $0.004 * * *$ & 1,727 & $\begin{array}{l}11.60 \\
(1.10)\end{array}$ & $\begin{array}{l}11.44 \\
(1.10)\end{array}$ & $0.012 * *$ \\
\hline Any anemia & 1,368 & $\begin{array}{c}0.41 \\
(0.49)\end{array}$ & $\begin{array}{c}0.50 \\
(0.50)\end{array}$ & $0.007 * * *$ & 1,727 & $\begin{array}{c}0.42 \\
(0.49)\end{array}$ & $\begin{array}{c}0.49 \\
(0.50)\end{array}$ & $0.019 * *$ \\
\hline Mild anemia & 1,368 & $\begin{array}{c}0.18 \\
(0.38)\end{array}$ & $\begin{array}{c}0.21 \\
(0.41)\end{array}$ & 0.14 & 1,727 & $\begin{array}{c}0.18 \\
(0.38)\end{array}$ & $\begin{array}{c}0.21 \\
(0.40)\end{array}$ & 0.12 \\
\hline $\begin{array}{l}\text { Moderate/severe } \\
\text { anemia }\end{array}$ & 1,368 & $\begin{array}{c}0.24 \\
(0.42)\end{array}$ & $\begin{array}{c}0.29 \\
(0.45)\end{array}$ & $0.068 *$ & 1,727 & $\begin{array}{c}0.24 \\
(0.43)\end{array}$ & $\begin{array}{c}0.28 \\
(0.45)\end{array}$ & 0.14 \\
\hline
\end{tabular}

Cognitive test outcomes

Block design

$1,395 \quad 3.54 \quad 3.75$

$(2.22)$

(2.19)

0.31

1,770

3.69

$(2.25)$

3.80

0.57

Digit span forward

$1,395 \quad 4.03$

4.09

0.46

1,770

4.07

(1.02)

(2.19)

(0.99) (0.99)

Digit span backward

1,39

$1.07 \quad 1.15$

0.49

1,770

1.10

(1.29)

4.09

(0.99)

(1.27) (1.30)

0.67

1,770

4.81

(1.65)

1.14

(1.30)

Progressive matrices $\quad 1,395$

4.75
$(1.62)$

(1.69)

Day and night

$1,395 \quad 5.23$

5.24

(3.45)

0.99

1,770

5.46

(3.49)

4.69

(1.71)

Cognitive score

$1,395 \quad-0.07$

$(3.37)$

index

(1.00)

$-0.01$

(0.97)

0.57

1,770

0.00

(1.02)

5.27

(3.37)

$0.00 \quad 0.96$

Educational outcomes

Math score

$\begin{array}{ccc}1,395 & 4.61 & 4.55 \\ & (3.83) & (3.73)\end{array}$

0.89

Reading score

$\begin{array}{lll}1,395 & 0.89 & 0.85\end{array}$

0.70

School attendance

1,334

(1.15)

(1.09)

0.54

0.72

0.72

(0.15)

(0.16)

Panel B: Demographics and socioeconomic variables

Muslim

$\begin{array}{lll}1,395 & 0.03 & 0.03\end{array}$

$(0.16)$

$(0.16)$

$\mathrm{SC} / \mathrm{ST}$

1,395

0.26

$(0.44)$

0.33

0.71

$(0.47)$

Block

1,395

$$
(0.45)
$$

0.59

Rural

1,395

0.97

$(0.49)$

(0.16)

0.98

Family size

1,39

7.75

(3.34)

(0.13)

7.57

(3.13) $\begin{array}{lll}0.94 & 1,770 \quad 0.03\end{array}$

(0.16)

0.03

(0.17)

$0.18 \quad 1,770$

0.25

(0.43)

0.31

(0.46)

0.25

1,770

0.71

(0.45)

0.63

$(0.48)$

1,770

0.97

(0.16)

0.98

(0.13)

7.68

(3.31)

1,770

(3.40)

0.91

0.22

0.41

0.54

0.43
1,770

4.91

(3.86)

4.75

(3.80)

1,770

0.95

(1.16)

0.87

(1.10)

1,678

0.79

(0.16)

0.79

(0.17)

0.69

0.45

0.64 


\begin{tabular}{|c|c|c|c|c|c|c|c|c|}
\hline $\begin{array}{l}\text { Father's years of } \\
\text { schooling }\end{array}$ & 1,395 & $\begin{array}{c}5.43 \\
(4.75)\end{array}$ & $\begin{array}{c}5.42 \\
(4.82)\end{array}$ & 0.97 & 1,770 & $\begin{array}{c}5.38 \\
(4.82)\end{array}$ & $\begin{array}{c}5.52 \\
(4.87)\end{array}$ & 0.70 \\
\hline $\begin{array}{l}\text { Mother's years of } \\
\text { schooling }\end{array}$ & 1,395 & $\begin{array}{c}1.78 \\
(3.22)\end{array}$ & $\begin{array}{l}1.66 \\
(3.08)\end{array}$ & 0.62 & 1,770 & $\begin{array}{c}1.80 \\
(3.26)\end{array}$ & $\begin{array}{c}1.78 \\
(3.22)\end{array}$ & 0.92 \\
\hline Asset index & 1,395 & $\begin{array}{c}0.02 \\
(0.99)\end{array}$ & $\begin{array}{l}-0.02 \\
(1.01)\end{array}$ & 0.65 & 1,770 & $\begin{array}{l}-0.01 \\
(0.96)\end{array}$ & $\begin{array}{l}-0.04 \\
(0.99)\end{array}$ & 0.70 \\
\hline Distance to school & 1,395 & $\begin{array}{l}10.18 \\
(6.00)\end{array}$ & $\begin{array}{l}10.63 \\
(6.46)\end{array}$ & 0.44 & 1,770 & $\begin{array}{l}10.25 \\
(5.96)\end{array}$ & $\begin{array}{l}10.52 \\
(6.55)\end{array}$ & 0.63 \\
\hline Gender of the child & 1,395 & $\begin{array}{c}0.44 \\
(0.50)\end{array}$ & $\begin{array}{c}0.46 \\
(0.50)\end{array}$ & 0.46 & 1,770 & $\begin{array}{c}0.45 \\
(0.50)\end{array}$ & $\begin{array}{c}0.46 \\
(0.50)\end{array}$ & 0.73 \\
\hline \multicolumn{9}{|l|}{ Health care } \\
\hline $\begin{array}{l}\text { Institutional } \\
\text { delivery }\end{array}$ & 1,395 & $\begin{array}{c}0.40 \\
(0.49)\end{array}$ & $\begin{array}{c}0.37 \\
(0.48)\end{array}$ & 0.39 & 1,770 & $\begin{array}{c}0.39 \\
(0.49)\end{array}$ & $\begin{array}{c}0.38 \\
(0.49)\end{array}$ & 0.70 \\
\hline Health insurance & 1,395 & $\begin{array}{c}0.40 \\
(0.49)\end{array}$ & $\begin{array}{c}0.38 \\
(0.49)\end{array}$ & 0.70 & 1,770 & $\begin{array}{c}0.40 \\
(0.49)\end{array}$ & $\begin{array}{c}0.38 \\
(0.49)\end{array}$ & 0.60 \\
\hline Diarrhea & 1,395 & $\begin{array}{c}0.04 \\
(0.20)\end{array}$ & $\begin{array}{c}0.03 \\
(0.16)\end{array}$ & 0.26 & 1,770 & $\begin{array}{c}0.03 \\
(0.18)\end{array}$ & $\begin{array}{c}0.03 \\
(0.16)\end{array}$ & 0.49 \\
\hline Improved sanitation & 1,395 & $\begin{array}{c}0.08 \\
(0.26)\end{array}$ & $\begin{array}{c}0.08 \\
(0.27)\end{array}$ & 0.73 & 1,770 & $\begin{array}{c}0.08 \\
(0.27)\end{array}$ & $\begin{array}{c}0.09 \\
(0.29)\end{array}$ & 0.59 \\
\hline \multicolumn{9}{|l|}{ Jutrition } \\
\hline Diet diversity score & 1,395 & $\begin{array}{c}3.89 \\
(1.21)\end{array}$ & $\begin{array}{c}3.84 \\
(1.15)\end{array}$ & 0.60 & 1,770 & $\begin{array}{c}3.90 \\
(1.20)\end{array}$ & $\begin{array}{c}3.84 \\
(1.14)\end{array}$ & 0.53 \\
\hline $\begin{array}{l}\text { Number of } \\
\text { meals/day }\end{array}$ & 1,395 & $\begin{array}{c}3.00 \\
(1.11)\end{array}$ & $\begin{array}{c}3.07 \\
(1.04)\end{array}$ & 0.44 & 1,770 & $\begin{array}{c}3.01 \\
(1.08)\end{array}$ & $\begin{array}{c}3.04 \\
(1.05)\end{array}$ & 0.64 \\
\hline Food scarcity & 1,395 & $\begin{array}{c}0.82 \\
(0.38)\end{array}$ & $\begin{array}{c}0.81 \\
(0.39)\end{array}$ & 0.61 & 1,770 & $\begin{array}{c}0.80 \\
(0.40)\end{array}$ & $\begin{array}{c}0.80 \\
(0.40)\end{array}$ & 0.96 \\
\hline $\begin{array}{l}\text { Maternal health } \\
\text { knowledge }\end{array}$ & 1,395 & $\begin{array}{c}0.36 \\
(0.48)\end{array}$ & $\begin{array}{c}0.40 \\
(0.49)\end{array}$ & 0.36 & 1,770 & $\begin{array}{c}0.36 \\
(0.48)\end{array}$ & $\begin{array}{c}0.40 \\
(0.49)\end{array}$ & 0.23 \\
\hline \multicolumn{9}{|l|}{ Care taking behavior } \\
\hline $\begin{array}{l}\text { Help with } \\
\text { homework }\end{array}$ & 1,395 & $\begin{array}{c}0.18 \\
(0.38)\end{array}$ & $\begin{array}{c}0.14 \\
(0.35)\end{array}$ & 0.26 & 1,770 & $\begin{array}{c}0.17 \\
(0.38)\end{array}$ & $\begin{array}{c}0.16 \\
(0.36)\end{array}$ & 0.48 \\
\hline Time physical care & 1,395 & $\begin{array}{l}44.15 \\
(24.93)\end{array}$ & $\begin{array}{l}46.95 \\
(26.60)\end{array}$ & 0.22 & 1,770 & $\begin{array}{c}43.99 \\
(24.28)\end{array}$ & $\begin{array}{c}46.43 \\
(25.56)\end{array}$ & 0.25 \\
\hline School meetings & 1,395 & $\begin{array}{c}0.63 \\
(0.48)\end{array}$ & $\begin{array}{c}0.63 \\
(0.48)\end{array}$ & 0.94 & 1,770 & $\begin{array}{c}0.63 \\
(0.48)\end{array}$ & $\begin{array}{c}0.61 \\
(0.49)\end{array}$ & 0.75 \\
\hline Father at home & 1,395 & $\begin{array}{c}0.89 \\
(0.32)\end{array}$ & $\begin{array}{c}0.87 \\
(0.33)\end{array}$ & 0.51 & 1,770 & $\begin{array}{c}0.88 \\
(0.33)\end{array}$ & $\begin{array}{c}0.86 \\
(0.34)\end{array}$ & 0.56 \\
\hline \multicolumn{9}{|c|}{ anel C: School level covariates } \\
\hline Total enrollment & 106 & $\begin{array}{l}224.56 \\
(169.0)\end{array}$ & $\begin{array}{l}222.28 \\
(149.3)\end{array}$ & 0.94 & 107 & $\begin{array}{c}222.15 \\
(168.29)\end{array}$ & $\begin{array}{c}222.28 \\
(149.30)\end{array}$ & 0.99 \\
\hline Class size & 106 & $\begin{array}{c}29.15 \\
(20.50)\end{array}$ & $\begin{array}{c}27.52 \\
(12.63)\end{array}$ & 0.62 & 107 & $\begin{array}{c}28.87 \\
(20.41)\end{array}$ & $\begin{array}{c}27.52 \\
(12.63)\end{array}$ & 0.68 \\
\hline $\begin{array}{l}\text { Student-teacher } \\
\text { ratio }\end{array}$ & 106 & $\begin{array}{c}37.62 \\
(12.65)\end{array}$ & $\begin{array}{c}33.87 \\
(10.46)\end{array}$ & 0.099 & 107 & $\begin{array}{c}37.52 \\
(12.55)\end{array}$ & $\begin{array}{c}33.87 \\
(10.46)\end{array}$ & 0.11 \\
\hline $\begin{array}{l}\text { Calories of MDM } \\
\text { per child }\end{array}$ & 106 & $\begin{array}{l}69.84 \\
(21.57)\end{array}$ & $\begin{array}{c}68.04 \\
(25.62)\end{array}$ & 0.70 & 107 & $\begin{array}{l}69.57 \\
(21.45)\end{array}$ & $\begin{array}{c}68.04 \\
(25.62)\end{array}$ & 0.74 \\
\hline
\end{tabular}

Notes: This table presents summary statistics as well as p-values for the difference in the means t-tests between children in the treatment and the control schools. All variables shown are child-level characteristics from the baseline except for panel C, which shows school-level variables. SD: Standard deviation, MDM: Mid-day meal; SC/ST: Scheduled Caste/Scheduled Tribe are the social and economically disadvantaged groups; $\mathrm{N}$ : Number of observations. 
Table A5: Heterogeneous treatment effects on hemoglobin and anemia by household caste

\begin{tabular}{lcccc}
\hline & Hemoglobin & $\begin{array}{c}\text { Any } \\
\text { anemia }\end{array}$ & $\begin{array}{c}\text { Mild } \\
\text { anemia }\end{array}$ & $\begin{array}{c}\text { Moderate or } \\
\text { severe anemia }\end{array}$ \\
\hline Treat & $(1)$ & $(2)$ & $(3)$ & $(4)$ \\
Treat*SC/ST & $0.138^{*}$ & $-0.085^{* *}$ & -0.052 & -0.033 \\
& $(0.082)$ & $(0.038)$ & $(0.034)$ & $(0.033)$ \\
Mean dependent var & -0.030 & -0.018 & -0.024 & 0.006 \\
Child fixed-effects & $(0.149)$ & $(0.061)$ & $(0.052)$ & $(0.054)$ \\
Controls & 11.443 & 0.476 & 0.191 & 0.285 \\
Observations & Yes & Yes & Yes & Yes \\
\hline $\begin{array}{l}\text { Notes: Standard errors, clustered at the school level, are } \\
\text { coefficients are based on a DID estimation. Any anemia is defined as a hemoglobin value }<11.5 \mathrm{~g} / \mathrm{dl} \text {, } \\
\text { mild anemia is defined as a hemoglobin value } \geq 11 \&<11.5 \mathrm{~g} / \mathrm{dl} \text {, moderate/severe anemia is defined }\end{array}$ \\
$\begin{array}{l}\text { as a hemoglobin value }<\text { 11 g/dl. *, } * *, * * \\
\text { respectively. }\end{array}$
\end{tabular}


Table A6: Heterogeneous treatment effects on cognition and education by household caste

\begin{tabular}{|c|c|c|c|c|c|c|c|c|c|}
\hline & $\begin{array}{l}\text { Block } \\
\text { design }\end{array}$ & $\begin{array}{l}\text { Digit span } \\
\text { forward }\end{array}$ & $\begin{array}{l}\text { Digit span } \\
\text { backward }\end{array}$ & $\begin{array}{c}\text { Progressive } \\
\text { matrices }\end{array}$ & $\begin{array}{c}\text { Day and } \\
\text { night }\end{array}$ & $\begin{array}{l}\text { Cognitive } \\
\text { Index }\end{array}$ & $\begin{array}{l}\text { Math test } \\
\text { score }\end{array}$ & $\begin{array}{l}\text { Reading } \\
\text { test score }\end{array}$ & $\begin{array}{c}\text { School } \\
\text { attendance }\end{array}$ \\
\hline & (1) & (2) & (3) & (4) & (5) & (6) & (7) & $(8)$ & (9) \\
\hline \multirow[t]{2}{*}{ Treat } & -0.002 & -0.031 & 0.103 & 0.031 & 0.167 & 0.077 & $0.157^{*}$ & $0.160 *$ & -0.009 \\
\hline & $(0.093)$ & $(0.075)$ & $(0.096)$ & $(0.112)$ & $(0.101)$ & $(0.087)$ & $(0.092)$ & $(0.091)$ & $(0.024)$ \\
\hline \multirow[t]{2}{*}{ Treat* SC/ST } & -0.033 & -0.111 & $-0.264^{*}$ & 0.038 & -0.048 & -0.121 & -0.048 & -0.133 & 0.013 \\
\hline & $(0.120)$ & $(0.139)$ & $(0.152)$ & $(0.176)$ & $(0.157)$ & $(0.131)$ & $(0.150)$ & $(0.130)$ & $(0.034)$ \\
\hline $\begin{array}{l}\text { Mean of dependent } \\
\text { variable }\end{array}$ & -0.025 & -0.078 & -0.137 & -0.098 & -0.052 & -0.181 & -0.206 & -0.199 & 0.768 \\
\hline Child fixed-effects & Yes & Yes & Yes & Yes & Yes & Yes & Yes & Yes & Yes \\
\hline Controls & Yes & Yes & Yes & Yes & Yes & Yes & Yes & Yes & Yes \\
\hline Observations & 2,790 & 2,790 & 2,790 & 2,790 & 2,790 & 2,790 & 2,790 & 2,790 & 2,896 \\
\hline
\end{tabular}

